\title{
مدى تأثيروسائل التواصل الاجتماعي على التلوث اللغوي لدى طلاب عمادة البرامج التحضيرية بجامعة الإمام محمد بن سعود الإسلامية من وجهة نظرهم \\ محمد أحمد أحمد فتحي زغاري
}
أستاذ مساعد المناهج وطرائق تدريس اللغة العربية والدراسات الإسلامية- عمادة البرامج التحضيرية- جامعة الإمام محمد بن سعود الإسلامية dr_design2010@yahoo.com

الملخخص:

هدفت الدراسة الحالية إلى تحديد مدى تأثير وسائل التواصل الاجتماعي على التلوث اللغوي لدى طلاب عمادة البرامج التحضيرية بجامعة الإمام محمد بن سعود من وجهة نظرهم، ولتحقيق هذا الهدف قام الباحث بتحديد مفهوم التلوث اللغوي، وتصنيفاته، وأسبابه، وكذلك وسائل

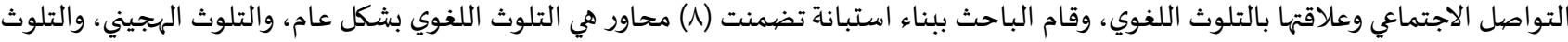

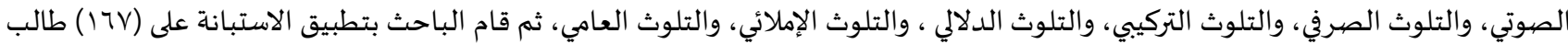

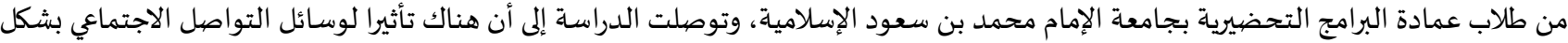
جزئي على التلوث اللغوي لدى عينة الدراسة.

الكلمات المفتاحية: التلوث اللغوي، وسائل التواصل الاجتماعي، طلاب عمادة البرامج التحضيرية. (ब) (1)

المقدمة:

تعد اللغة جزءًا أساسيًً في حياة الفرد والمجتمع وضرورة من ضرورات الحياة الاجتماعية، وتتضمن اللغة العربية أربعة فنون لغوية:

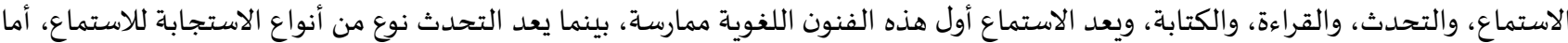

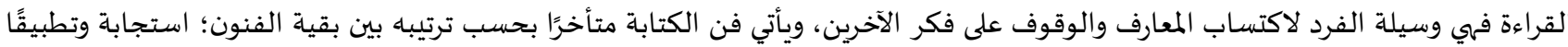
ل للفنون السابقة. وتشتمل اللغة على وظائف عديدة لعل أهمها وأبرزها بل وأقدمها هي الوظيفية التواصلية، فالتواصل لا يتم بين أفراد المجتمع إلا من خلال

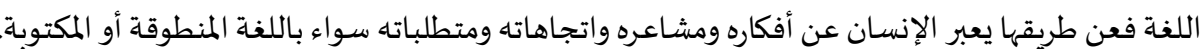

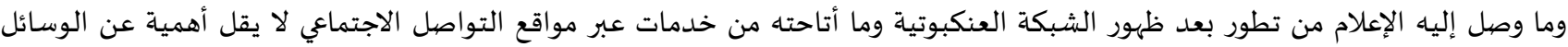

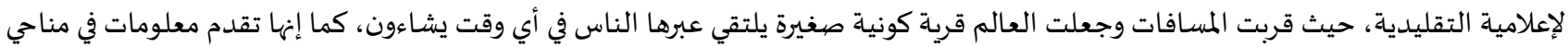

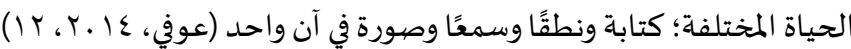

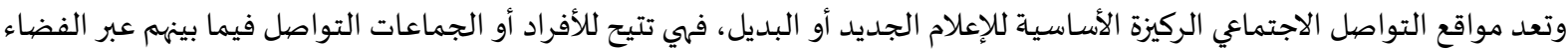

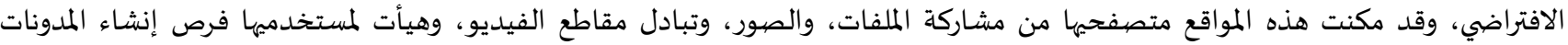

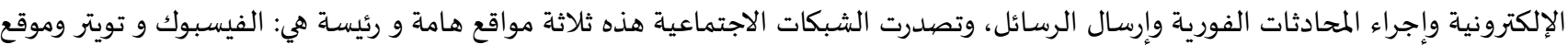

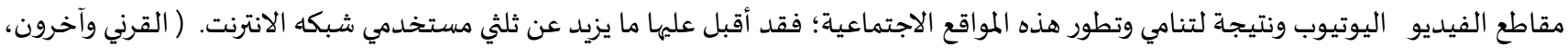

(Y) T. T.10 وتتميز اللغة العربية بقدرتها الفائقة على الاشتقاق وتوليد المماني، والألفاظ، وقدتها على التعريب، واحتواء الألفاظ من اللغات الأخرى،

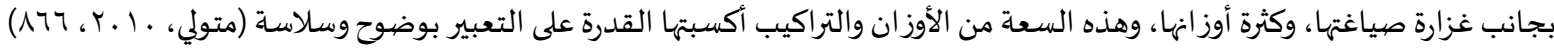

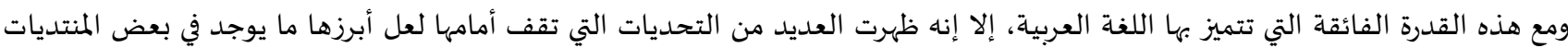

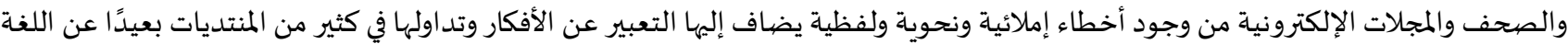

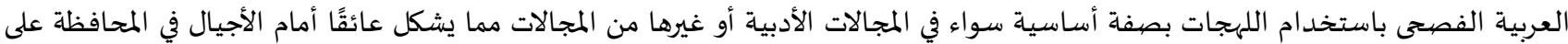

اللغة العربية (على، عا. .T، ع IV) وتعد ظاهرة التلوث اللغوي من الظواهر التي انتشرت بشكل واسع على مواقع التواصل الاجتماعي، وتتمثل هذه الظاهرة في: استخدام الكلمات الأجنبية على حساب اللغة العربية، وكذلك استخدام مزيج بين اللغة العامية والأرقام اللاتينية والرموز نتج عنه لغة ملوثية، وصاحبتها أثاريار 
ضارة على الاستخدام السليم للغة العربية، وبذلك أصبحت تمثل أحد أوجه الغزو الثقافي فالغرب متفوق على دول العالم العربي في الصناعة ، و بذلك

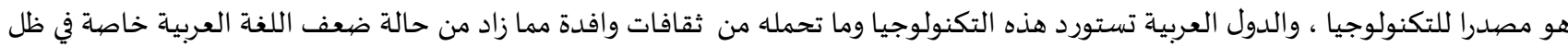

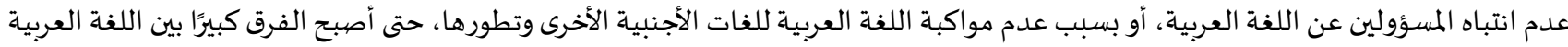

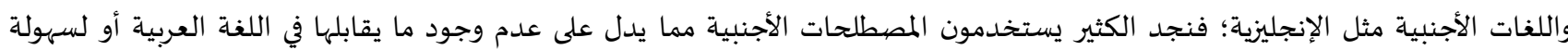

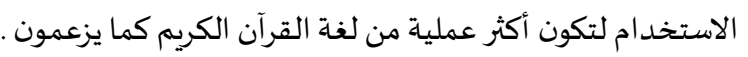

ويرى السلاموني (ع ا ـ r) أن من أهم أسباب التلوث اللغوي: انشغال الأهل في السعي وراء لقمأ العيش العيش والاهتمام بتوفير الاحتياجات المادية

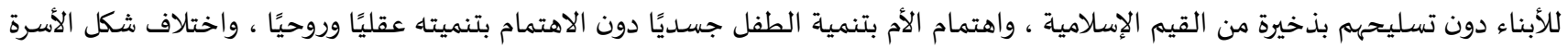

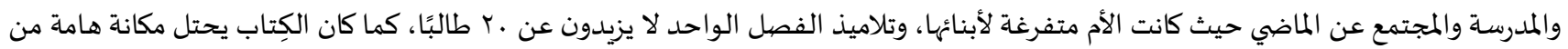

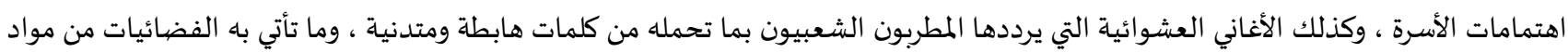
تدمر ثقافة ولغة الأطفال والكبار ، والتفكك الأسري وانتشار ظاهرة الطلاق ألقى بالأبناء في دائرة الفساد الأخلاقي.

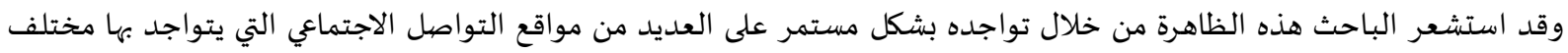

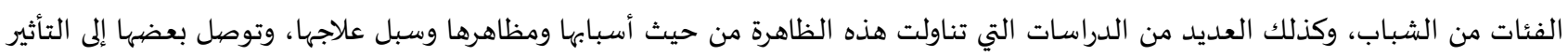

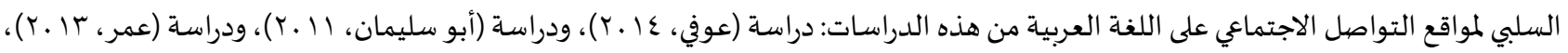

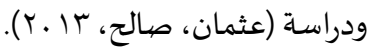

وكذلك نتائج بعض الدراسات التي أشـارت إلى استخدام نسبة كبيرة جدّا من الشباب لمواقع التواصل الاجتماعي منها دراسة سالم (Salim, 2017) التي توصلت إلى أن:

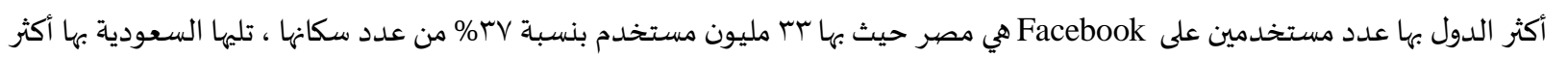

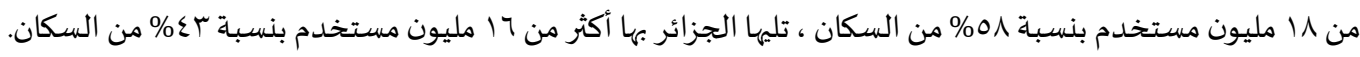

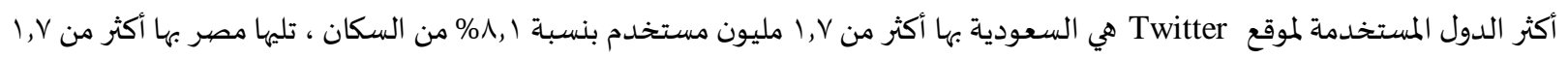

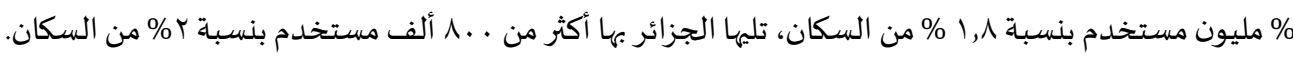

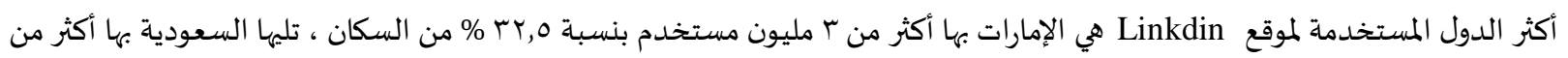

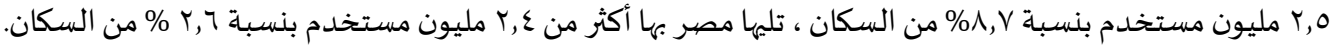

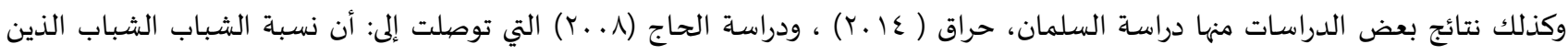

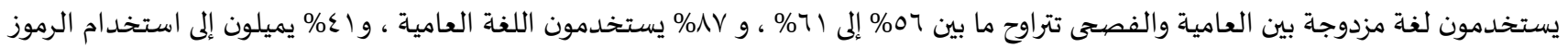
والاختصيارات.

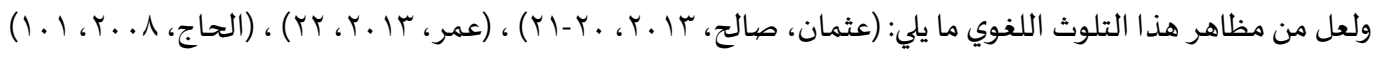

أ- فيما يتعلق بالكتابة:

• كثره الاخطاء اللغوية الشائعة المخالفة للمسموع من اللغة وأصولها الثابتة. • عدم السلامة في الأسلوب و تركيب الجمل تركيبًا ينمُ عن التكلف، وغلبة الركاكة. إهمال علامات الترقيم من فاصلة وقاطعة وشارحة وغيرها إهمالا تامًا.

المبالغة في استعمال الكلمات العامية في الصحافة العربية عمومًا.

الإكثار من استعمال الكلمات الأجنبية بلا داعٍ مع سهولة المقابل العربي لها.

ب- فيما يتعلق باللغة اللفظية:

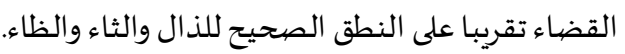
الوقف على التاء المقفلة تاء لا هاء في نحو فتاة، الزكاة. • أداء الكلام المكتوب بالفصحى بطريقة اللهجة العامية و بنبرات الحديث الدارج. غلبة اللهجات العامية المحلية على الفصحى في معظم الإذاعات المسموعاة والمرئية. إدخال الكاملام الهجين بكثرة إلى اللغة.

اتسام الأصوات المصاحبة للمقاطع المصورة، وكذلك التعليقات المرافقة للصور بالكثير من الإشكالات اللغوية من حيث النطق و المخارج. 
من مظاهر هذا التلوث اللغوي أيضّا بث لغة عامية محشوة بالأخطاء عبر وسائل الإعلام المختلفة، وكذلك ما ينشر على مواقع الإنترنت

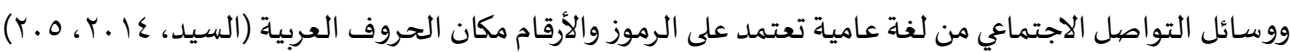

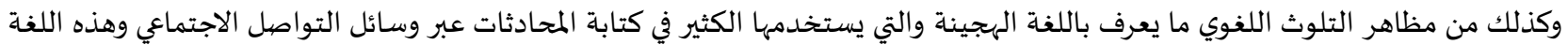
تفرضها بعض الظروف منها عدم توفر لوحة مفاتيح عربية على الأجهزة التي يستخدمونها، فأصبحوا يكتبون لغة إنجليزية بمعان عربية، وتسعى هذه

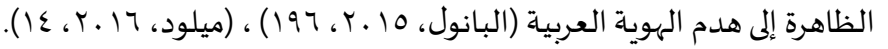

\section{الإطار النظري و الدراسـات السـابقة: التلوث اللغوي: 1. أشأة التلوث اللغوي:}

بدأت ظاهرة التلوث اللغوي نتيجة ظهور اللغة الهجينة التي اصطلح علها الشباب باسم العربيزي أو الفرانكو أراب مع نهاية الألفية الماضية و تنامت بشكل سريع في الأوساط الشبابية في العقدين الأخيرين من الألفية الثالثة، وهي ظاهرة لغوية وليدة الشبكة العنكبوتية ومواقع التواصل

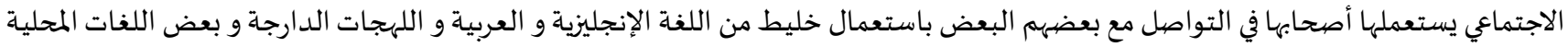

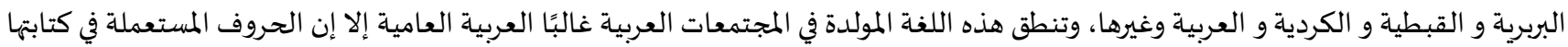
و التلفظ بها يغلب عليها الحرف اللاتيني مع استبدال حروف عربية بأرقام لاتينية وهذه اللغة أشباه ما تكون الشيفرة تستعمل في المواقع المختلفة

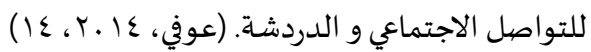
وهذا النسق اللساني الشبابي الجديد الذي ارتبط بمواقع التواصل الاجتماعي تغول بعدما بات يستمد خطره من الغموض الذي يتسم باه،

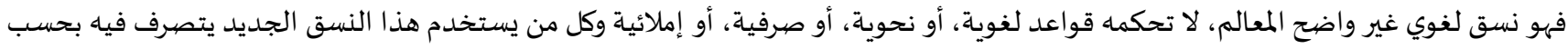

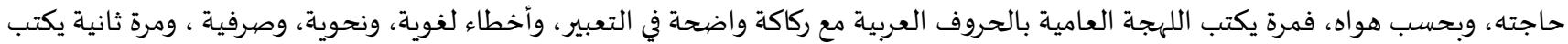

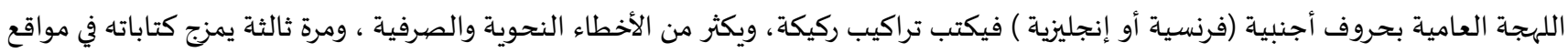
التواصل الاجتماعي بين نسق لساني مكون من النسقين اللسانيين السابقين، ونسق ثالث إيقوني في شكل صور مثل: ، ، ؛ لذلك فإن نتيجة هذه الصدمات

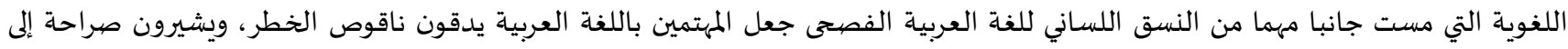
خطورة مثل هذه الأنساق اللغوية على اللغة العربية. r. ت تعريف التلوث اللغوي: تعرف المنصور (ع ا.r، ror) التلوث اللغوي بأنه تداخل الأعجمية بالعربية تولد عنه لغة كتابه تسمى اللغة الهجين أسماها الشباب بالعبيزي لوثت اللغه المكتوبة بالعجمة والرقمنة و الرموز التصويرية وغيرها.

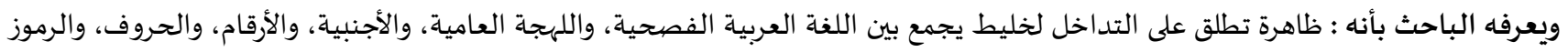
ليكون تراكيب جديدة على مجتمعنا، يتفوه بها الشباب أو يكتبونها، وتتسم بعدم وجود قواعد تتميز بالثبات والدقة تتشكل على أساسها الكلمات

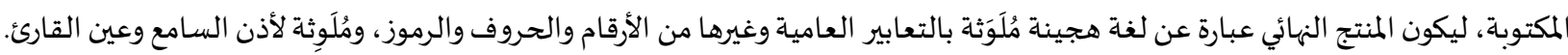

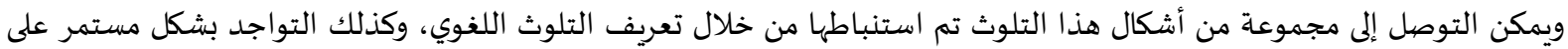

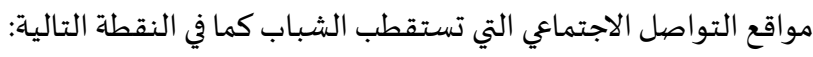

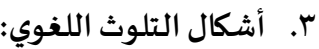

التلوث الصهوتي: وهو التلوث الناتج عن إبدال حرف بحرف مثل: إبدال الكاف في كلمة "لبَّيك" بالهاء لتكون "لبَّيَه"، أو إبدال حركة بأخرى مثل:

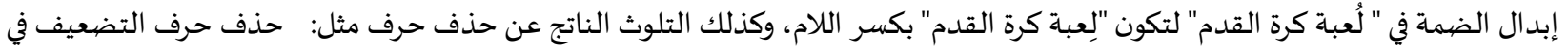

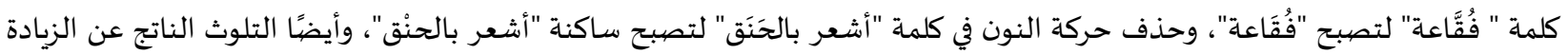

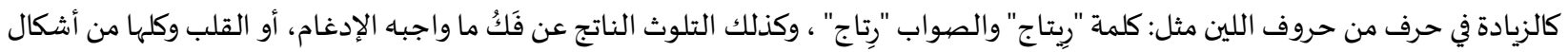

$$
\text { التلوث المتصلة بأصوات اللغة العربية "الصوامت" و حركاتها "الصوائت". }
$$

التلوث الصرفي: وهو التلوث المتصل بالأبنية الصرفية، سواء أكانت أبنية أسماء أم أبنية أفعال، على سبيل المثال للتلوث المتصل بأبنية الأسماء:

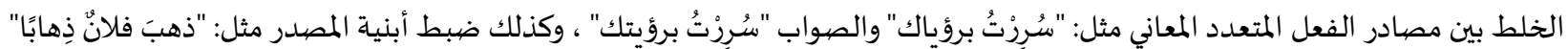

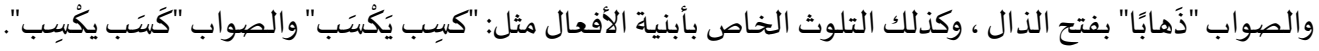


التلوث التركيبي: وهو التلوث المتصل بالأغلاط النحوية، وله أشكال متعددة منها على سبيل المثال: إدخال حرف التعريف على "لا" النافية فمثلا يقال: "هذا من اللامعقول" والصواب "هذا من غير المعقول"، وكذلك التوظيف المخطئ للأداة النحوية مثل: "كلما ذاكرت دروسك كلمات كلما نجحت

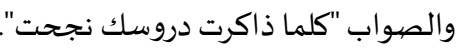

التلوث الدلالي: وهو التلوث المتصل بالدلالة، ولها أشكال كثيرة منها: قلب المعنى ومثال ذلك " استقل فلان سيارته" والصواب "استقلَّتَهُ سيارتُه"،

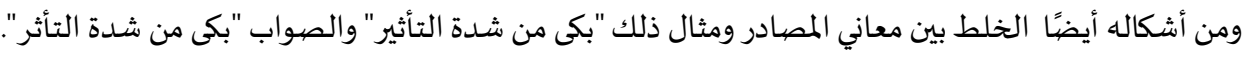

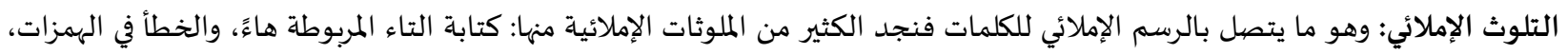
والخلط بين واو الجماعة وعلامة رفع المذكر السالم، والخلط بين التاء المفتوحة والمبروطة، وكتابة همزة الوصل همزة قطع والعكس، وعلامات الترقيم.

التلوث الهجيني: وهو عمل هجين من اللغة العربية وغيرها من اللغات الأخرى كالأجنبية أو الفرنسية مما ينتج عنه شكل جديد يسمى أحيانًا

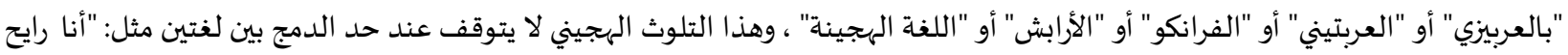

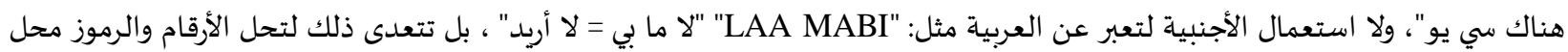
الحروف ومثال ذلك: "La2 nesait:p" وتعنى "لا نسيت "والرمز p: يشير إلى وجاه يدل على على الغضبه.

التلوث العامي: وهو خلط اللغة العربية الفصحية بالألفاظ العامية الدارجة مما ينتج عنها لغة مشوهة لا يمكن اعتبارها فصحى ولا يمكن

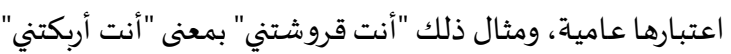
وبالرجوع إلى كافة أشكال الملوثات السـابقة نجد أنها تصنع لنا مفهومًا جديدًا هو التلوث اللغوي الذي هو عبدارة عن مزيج من التلوث الصهوتي،

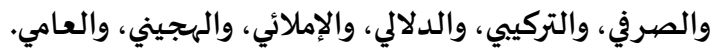

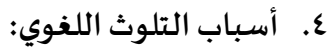

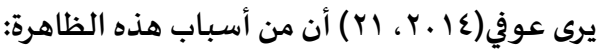
ظهور برامج الدردشة في التسعينات التي لم تتح سوى الحروف اللاتينية للكتابة، مما أجبر الكثير من العرب على استخدام الحروف اللاتينية،

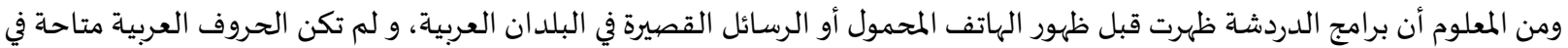

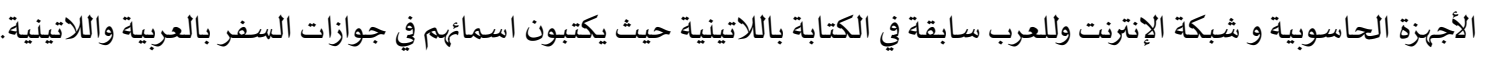

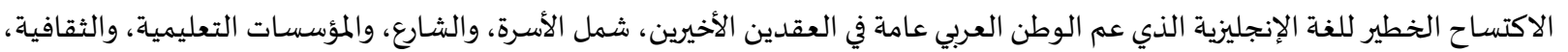
والاقتصادياة، والاجتماعياة، والإدارية، و السياسية جعل الإنسان العربي- ولاسيما الشباب منه- إذا لمانية يستعمل هذه اللغة أو غيرها،

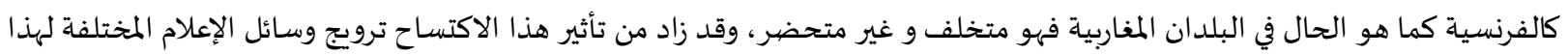

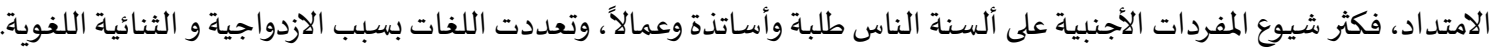
الكثير من المحطات الفضائية العبية التلفزيونية المحطات الإذاعية من برامج و لقاءات، فقد أصبح الكثير منها يقدم باللغة العامية مع العادية الابتعاد تمامًا عن اللغة العربية الفصحى، بل وإدراج كلمات من اللغة الإنجليزية في كلام تلك البرامج بدلا من إدراج اللغة الفصيهى. كما أن الغاية تحقيق التواصل بين مستعملي العربية والعمالة الوافدة التي تتعدد لغاتها حسب انتماءاتها لأن هذه العمالة جاءت إلى المملكة وهي لا تعرف شيئًا عن اللغة العربية ولم تخضع لتعليم رسمي وغير رسمي عن اللغة العربية، و مع ضرورة تواصلها مع المجتمع الجديد الذي قدمت إليه كان ولابد من تطوير لغة سهلة ومبسطة لتتواصل مع لغة لغة هذه الثقافة الجديدة طغيان الثقافة العبية وسيطرة الإنجليزية على البرامج التعليمية الجامعية جعل الطلاب والطالبات ينظرون إلى اللغة العربية نظرة ازدراء

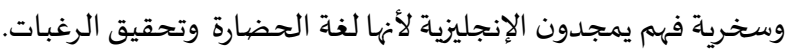
يرى الكثير من المتخصصين والمعنيين بشؤون العربية الفصحى أن الإعلام له دور خطير في ذيوع وانتشار ظاهرة العبيزية.

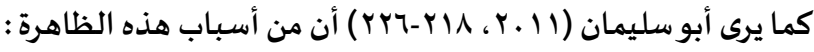

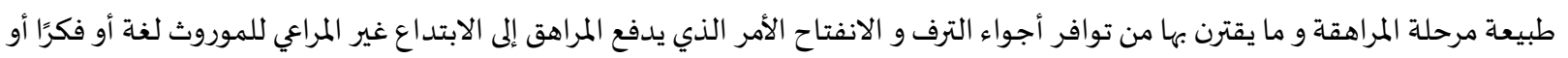
عادات أو أعرافا. رياء الأناو المحاكاة العمياءو هو يتمثل في التمظهر الكاذب و الزهو بمعرفه لغة غريبة أو أجنبية، والقدرة على الابتداع في لغته. المشكلات التي تواجه الشباب في الوطن العربي و التي منها البطالة وعدم الاهتمام بقدرات ومواهب الشباب. حالة العرب اليوم حيث يعانون من الانزواءو الانكفاء على معالجة المشاكل التي يدبرها الأعداء و عدم القدرة على ملاحقة ومواكبة التقدم و الازدهار ، مما انعكس على لغتهم. 
•التنشئة الأسرية والمجتمعية حيث ضعف المتابعة والمراقبة، و قلة العناية بالأبناءو خاصة في مرحلة الشباب. المؤسسة الإعلامياة حيث تسهم بعض وسائل الإعلام العربية في بعض برامجها و مسلسلاتها و أفلامها و أقلامها في إضعاف تمسك الشباب

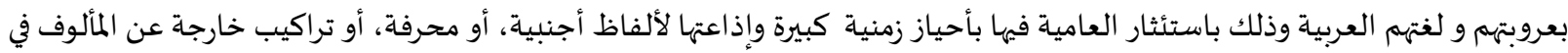

المؤسسة التعليمية حيث ضعفت المؤسسة التعليمية التربوية، والتثقيفية، والدينية في تحصين الشباب ضد الخروج على الموروث اللغوي. وسائل التواصل الاجتماعي.

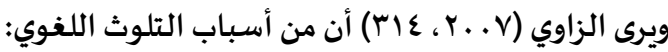

مخلفات الاستعمار، والتدفق المصطلحي للتكنولوجيات الحديثة، وكذلك اليد العاملة الوافدة، وهذا السبب خاص العاص ببلدان الخليج. من خلال عرض الباحث للسابق تأكد له أن حصر هذه الأسباب ليس بالأمر السهل؛ وذلك لتفاوت تأثير تلك الأسباب في نشأتها ونموها، كما أنه موضوع شائك يتداخل فيه العديد من العناصر ؛ لذا سيحاول الباحث التوصل إلى مجموعة من أهم أسباب التلوث اللغوي عند الثد الشباب بالمملكة العربية السعودية بشكل خاص و مجمل على النحو التالي: أسباب ثقافية اجتماعية:

انفتاح المجتمع السعودي على الثقافات الغربية أدى إلى دمج بعض المفردات الأجنبية في اللغة العربية بشقهيا المكتوب والمنطوق، بالإضافة

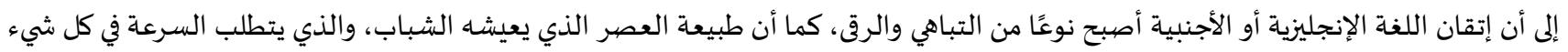

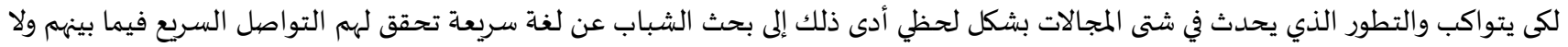

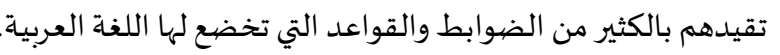
أسباب نفسية : n

يعتبر من الأسباب النفسية عدم اعتزاز الشباب بلغتهم وأهمية الحفاظ عليها ؛ أدى ذلك إلى ضعف الوعى اللغوي لديهه، وتعتبر هذه مسئولية

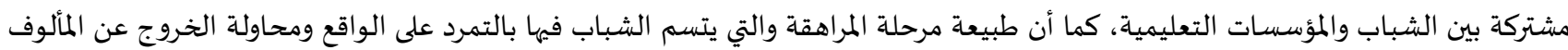
جعلت الشباب يستمتعون بهذه اللغة التي يتواصلون بها والتي تحتاج من الآخرين التعرف على قواعدها غير الثابتة حتى يستطيعوا فهمها.

• أسبباب تعليمية:

قلة الثقة باللغة العربية ومقدرتها للاستجابة للتحديات المعاصرة وقدرتها أن تكون حاملة للمعرفة مثلما كانت حافظة للتراث وناقلة له،

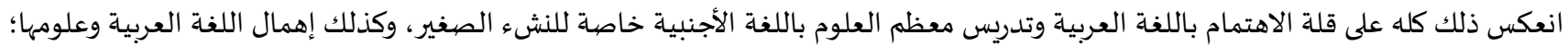

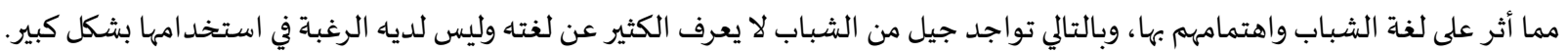
• تتمثل الأسباب العالمية في حالة الضعف التي يعيشها العرب في شتى أرجاء المعمورة، وعدم القدرة على مواكبة التطور الكبير والسريع الذي

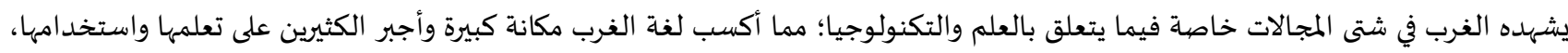
بالإضافة إلى ظهور برامج الدردشاة ومواقع التواصل الاجتماعي التي باتت من الأمور التي لا يستطيع الفرد الابتعاد عنها كليًا أو إغفالها كوسيلة من وسائل التواصل الاجتماعي الحديثة.

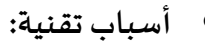

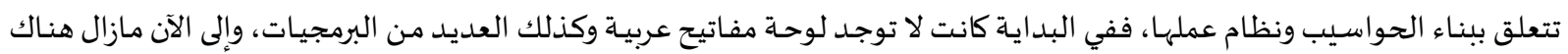

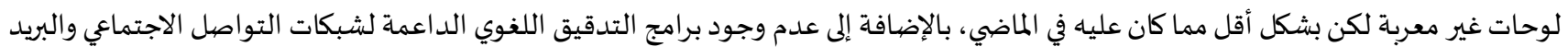
الإلكتروني وغيرها.

0. الأثار السلبية للتلوث اللغوي: تعتبر من أشـد الأثار السلبية لهذه الظاهرة واقعًاو تأثيرًا و سـرعة في الانتشـار الانحراف في الرسم الكتابي فبعد أن تشـوهت اللغة ملفوظة

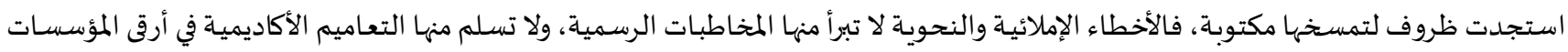

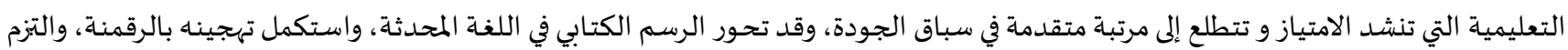

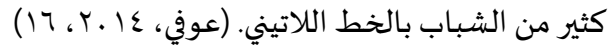

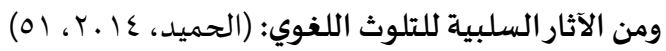


اسـتخدام هـذه اللغـة قـد يؤدي الى قلـة اسـتخدام اللغـة العربيـة وهـا الأمـر يقـود بطبيعـة الحـال إلى ضـعف التحـدث باللغـة العربية أو إتقان مهاراتها النحوية والإملائية واللغوية. كثره استخدامها يؤدي إلى ضعف المحتوى العربي في الإنترنت و تقليله بشكل عام. تقليل الاعتزاز باللغة العبية والدفاع عنها وتسويتها باللغات الأخرى من حيث توفير الدعم اللازم لها من قبل الشركات المصنعة وصنع القرار

\section{مو اقع التواصل الاجتماعي:}

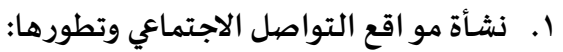

نشأت مواقع التواصل الاجتماعي الإلكتروني في الولايات المتحدة الأمريكية بفضل شواعل شبكة الإنترنت، وفي عام 1990 تم إطلاق موقع كلاس

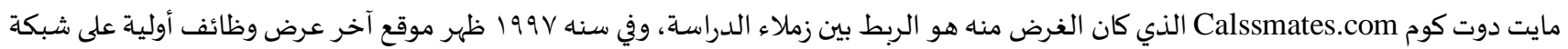

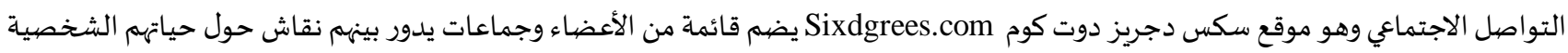
بغض النظر عن انتمائاتهم العرقية والدينية أو الثقافية ، حيث سمح هذا الموقع بإنشاء ملفات شخصية مع إرسال الرسائل الخاصة إلى الأصدقاء لكن

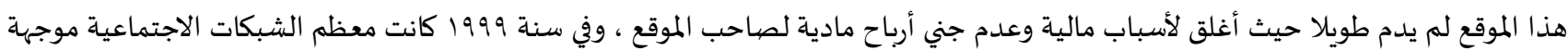
للشعب الأسيوي و إلى ذوي البشرة السمراء ، وفي سنة r . . ت تم إطلاق موقع فرندستر دوت كوم Frendster.com هذا الموقع لاقى رواجًا كبيرًا؛ حيث

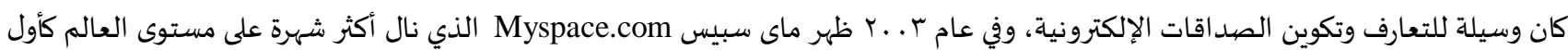
شبكة اجتماعية مفتوحة، وفي سنه ع . . Y ظهر موقع آخر وهو الفيسبوك Facebook.com على يد مارك زوكربيرج وأصبح الموقع الأكثر رواجًا على الى

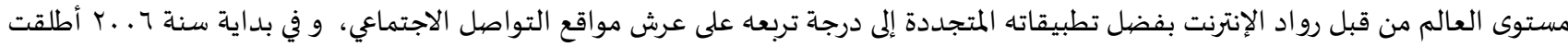
شركة أودي الأمريكية موقع تويتر مع ظهور المدونات الصغيرة، كما ظهرت مواقع التواصل الاجتماعي حسب الاختصاص أو المهن المختلفة. (فوزي،

$(Y \varepsilon Y-Y \leqslant 7$ ، $Y$. )

\section{r . تعريف مو اقع التواصل الاجتماعي:}

مو اقع التواصل الاجتماعي هي: مجموعة من المواقع على شبكة الإنترنت تتيح التواصل بين عدد كبير من المستخدمين يجمع بين أفرادها

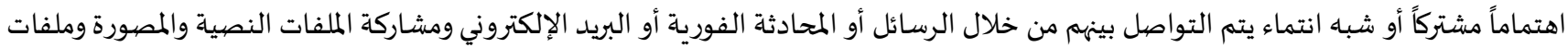
الفيديو والصوتيات، وهي وسيلة فعالة للتواصل الاجتماعي بين الأفراد سواء أكانوا أصدقاء معروفين في الواقع أم أصدقاء تم التهاء التعرف عليهيه من خلال

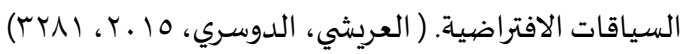

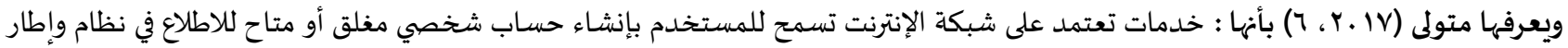

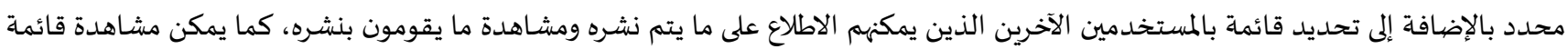
بمن يتواصلون معهم داخل إطار المنصية وقواعدها. أنواع شبكات التواصل الاجتماعي:

$$
\text { تصنف شبكات التواصل الاجتماعي حسب الأهداف التي تسعى إلى تحقيقها على النحو التالي: }
$$

شبكات التنشئة الاجتماعية : وهي الشبكات التي أنشئت من أجل الترفيه والتواصل الاجتماعي بين الأعضاء وغالبًا ما تستخدم للعثور وعرض التهاء

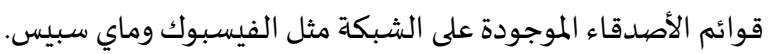
شبكة التواصل الاجتماعي : هي الشبكة التي تستخدم من أجل إيجاد علاقات جديدة، وتضيم عددًا كبيرًا من أسماء المستخدمين غير المعروفة مثل موقع لينكد إن. الشبكات الاجتماعية للابحار : وهي وسيلة لمساعدة المستخدمين على إيجاد نوع من المعلومات أو المصادر، كما تستخدم من أجل نشر قوائم

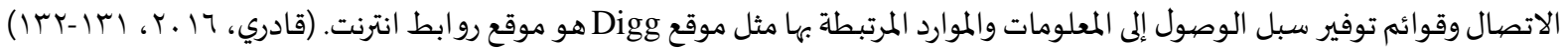

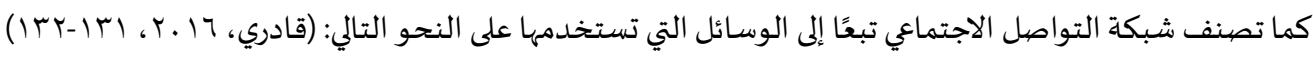
الشبكات الاجتماعية العامة مثل : فيسبوك وماي سبيس. المدونات مثل : سكاي بلوج و ويكيبيديا. أدوات التشارك لتسجيلات الفيديو من اليوتيوب والموسيقى مثلا ديزر والصيور مثل : فلكر أر.

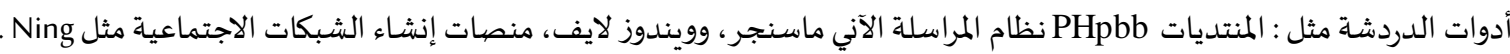
وسائل الإشهار الصغيرة تويتر والمواقع المشتقة منها تويتكسر إضافة إلى غيرها من المواقع الأخرى التي تربط شعوب العالم تحت موضوع مشترك 
r. تأثيروسائل التواصل الاجتماعي على اللغة العربية:

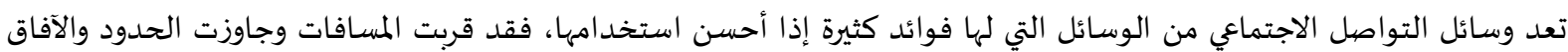
وجمعت بين الشتات وأصبحت ملتقى يجمع فياء الناس الذين تناءت ديارهم وتباعدت أوطانهم، والذين لم يكونوا يحلمون بالاجتماع حول مائدة واحدة

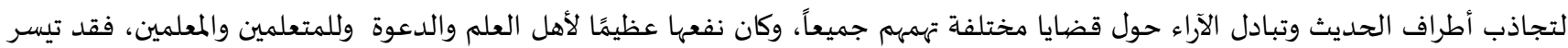
لهؤلاء وأولئك الوصول إلى بغيتهم وإجابات تساؤلاتهم وإشكالاتهم بأسرع طريقة إلى غير ذلك من فوائد ومنافع هذه الوسائل المستحدثاءة. فهي وإن كانت

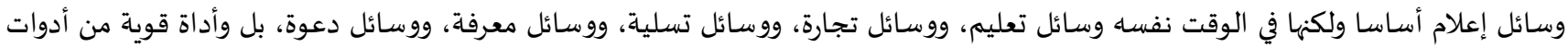

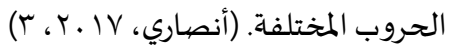
ويعتبر انتشار وسائل التواصل الاجتماعي عاملا مهمًا في التأثير على اللغة سلبًا لأن مستخدمي شبكة التواصل الاجتماعي ليسوا على مستوى

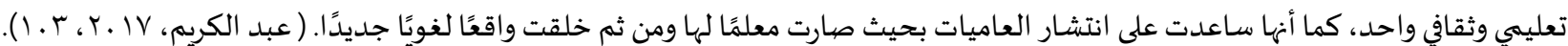

تحسديد المشكلة:

تتحدد مشكلة البحث الحالي في بحث مدى تأثير مواقع التواصل الاجتماعي على التلوث اللغوي لدى طلاب عمادة البرامج التحضيرية بجامعة

الإمام محمد بن سعود الإسلامية من وجهة نظرهم، ويمكن تحديد مشكلة البحث الحالي في السؤال التالي: ما مدى تأثير مو اقع التواصل الاجتماعي على التلوث اللغوي لدى طلاب عمادة البرامج التحضيرية بجامعة الإمام محمد بن سعود الإسلامية من وجهة نظرهم؟

فروض البحث:

يوجد أثر بدرجة كبيرة لاستخدام وسائل التواصل الاجتماعي على التلوث اللغوي لدى طلاب عمادة البرامج التحضيرية بجامعة الإمام محمد

بن سعود من وجهة نظرهم، ويتفرع من هذا الفرض الرئيس الفروض التردئ التالية:

يوجد أثر بدرجة كبيرة لاستخدام وسائل التواصل الاجتماعي على التلوث اللغوي (التلوث اللغوي بشكل عام) لدى طلاب عمادة البرامج

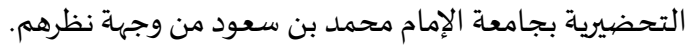

يوجد أثر بدرجة كبيرة لاستخدام وسائل التواصل الاجتماعي على التلوث اللغوي (التلوث الهجيني) لدى طلاب عمادة البرامج التحضيرية

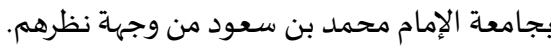
يوجد أثر بدرجة كبيرة لاستخدام وسائل التواصل الاجتماعي على التلوث اللغوي (التلوث الصوتي) لدى طلاب عمادة البرامج التحضيرية

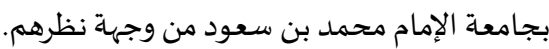
يوجد أثر بدرجة كبيرة لاستخدام وسائل التواصل الاجتماعي على التلوث اللغوي (التلوث الصرفي) لدى طلاب عمادة البرامج التحضيرية بجامعة الإمام محمد بن سعود من وجهة نظرهم. يوجد أثر بدرجة كبيرة لاستخدام وسائل التواصل الاجتماعي على التلوث اللغوي (التلوث النحوي) لدى طلاب عمادة البرامج التحضيرية

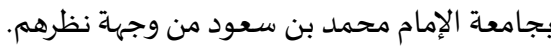
يوجد أثر بدرجة كبيرة لاستخدام وسائل التواصل الاجتماعي على التلوث اللغوي (التلوث الدلالي) لدى طلاب عمادة البرامج التحضيرية بجامعة الإمام محمد بن سعود من وجهة نظرهم. يوجد أثر بدرجة كبيرة لاستخدام وسائل التواصل الاجتماعي على التلوث اللغوي (التلوث الإملائي) لدى طلاب عمادة البرامج التحضيرية بجامعة الإمام محمد بن سعود من وجهاة نظرهم. يوجد أثر بدرجة كبيرة لاستخدام وسائل التواصل الاجتماعي على التلوث اللغوي (التلوث العامي) لدى طلاب عمادة البرامج التحضيرية بجامعة الإمام محمد بن سعود من وجهة نظرهم.

أهمية البحث:

رغم وجود العديد من الدراسات التي تناولت مواقع التواصل الاجتماعي باعتبارها أحد المستحدثات التي فرضتها التكنولوجيا الحديثة والتي انتشرت بشكل واسع، إلا إنه لم توجد دراسة - في حدود علم الباحث - تناولت العلاقة بين مواقع التواصل الاجتماعي وظاهرة التلوث اللغوي كأحد الظواهر التي تنامت في ظل مواقع التواصل الاجتماعي، وبالتالي تتجلى أهمية البحث الحالي في: تناول ظاهرة هامة من الظواهر التي تنامت حديثًا وهي ظاهرة التلوث اللغوي. 
تناول موضوع حديث ومرتبط بالحياة والعلاقات الاجتماعية وكذلك التكنولوجيا الحديثة وهو مواقع التواصل الاجتماعي. تحليل نتائج ومعطيات عينة من الشباب السعوديين الجامعيين باعتبارهم العنصر الأنشط في المجتمع السعودي، ولهم الدور الأهم في الإنتاج والتطور.

أن يكون البحث الحالي نواة لسلسة من الأبحاث التي تتناول التلوث اللغوي بشكل أكثر تفصيلا وعمقًا.

$$
\text { يلتزم البحث البحالي بالحدود التالية: }
$$

مصطلحات البحث:

التلوث اللغوي: تعرف المنصور (عا ـr ، ror) التلوث اللغوي بأنه تداخل الأعجمية بالعربية تولد عنه لغة كتابه تسمى اللغة الهجين أسماها الشباب بالعربيزي لوثت اللغة المكتوبة بالعجمة والرقمنة و الرموز التصويرية وغيرها.

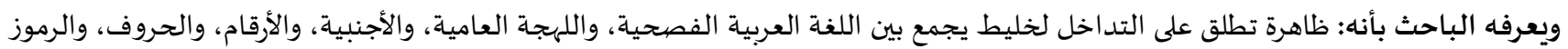
ليكون تراكيب جديدة على مجتمعنا، يتفوه بها الشباب أو يكتبونها، وتتسم بعدم وجود قواعد تتميز بالثبات والدقة تتشكل على أساسها الكلمات

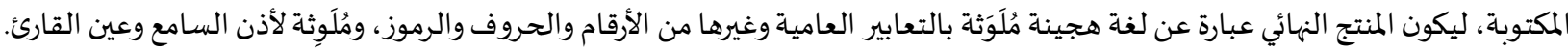
مو اقع التواصل الاجتماعي: هي خدمة تواصل اجتماعي Service Networking Social من خلال منصات فريدة من نوعها تشجع على المشاركة

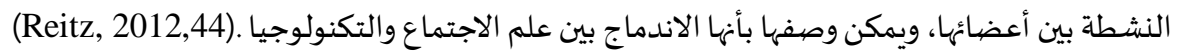

$$
\text { أولاً: منهراءات الدراسـة: }
$$

نظرًا لأن الهدف الرئيس من الدراسة الحالية هو تحديد مدى تأثير مواقع التواصل الاجتماعي على التلوث اللغوي لدى طلاب عمادة البرامج

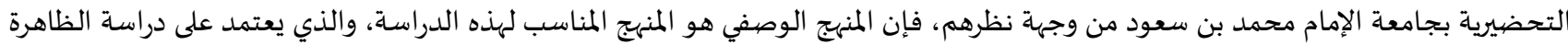

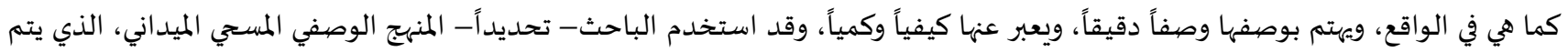

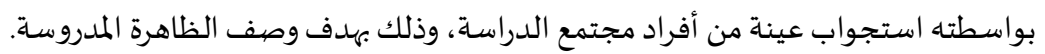

ثانياً: بناء أداة الدراسة (الاستبانة)

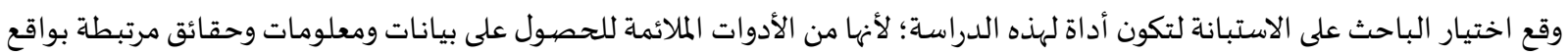

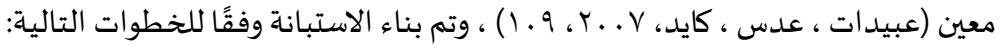

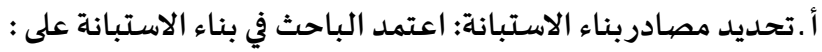
الدراسات والبحوث المرتبطة بالتلوث اللغوي، ومواقع التواصل الاجتماعي. استطلاع رأى أجرى على عينة من طلاب الجامعة. ب. بناء الاستبانة في صورتها الأولية: في ضوء المصادر السابقة، تم بناء الاستبانة في صورتها الأولية، وقد اشتملت على غلاف ومقدمة تخاطب المحكمين، ثم الجزء الأول من

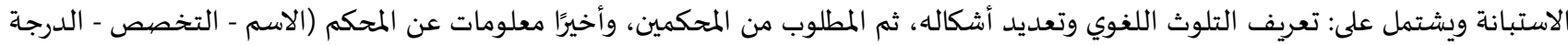

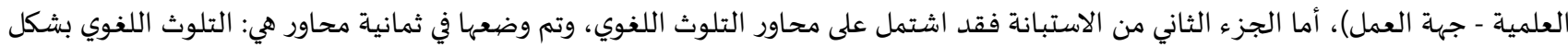

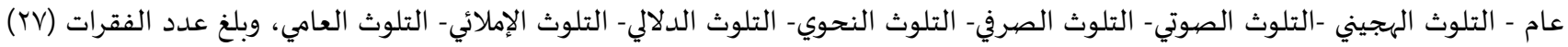

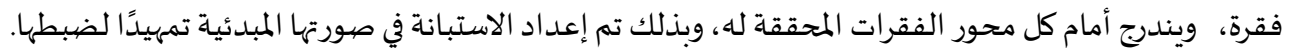

ج ج.ضبط الاستبانة:

تم ضبط الاستبانة والتحقق من صدقها وثباتها وفقًا للخطوات التالية:

د - صيدق الاستبانة:

تم التحقق من صدق الاستبانة وأنها صالحة لقياس ما وضعت من أجله وذلك من خلال: 
التأكد من الصـدق الظاهري للاستبانة: وتم ذلك من خلال عرض الاستبانة في صورتها المبدئية على عدد من المحكمين المتخصصين في المنـاهج

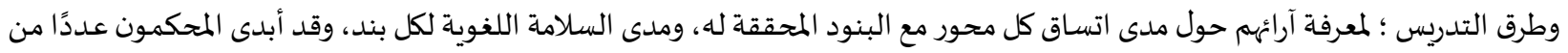

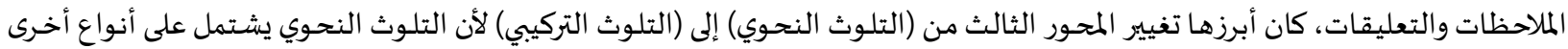

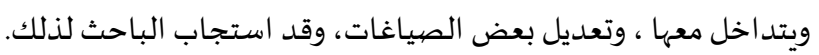

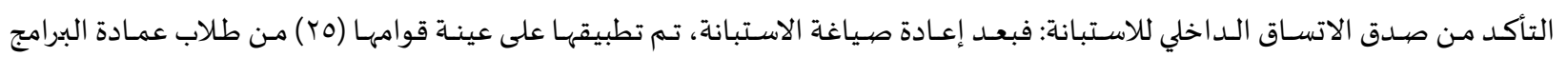
التحضيرية بجامعة الإمام محمد بن سعود الإسلامية (من غير العينة الأصلية للدراسـة الحالية)، وقـد تم حساب معاملات الارتباط بين درجة كل

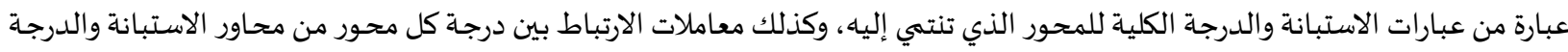

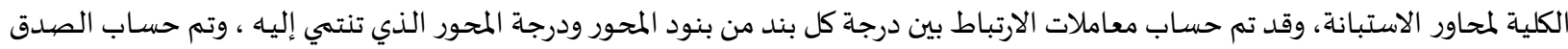

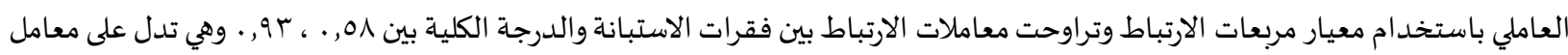

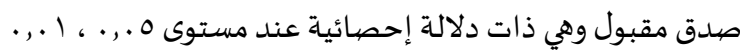

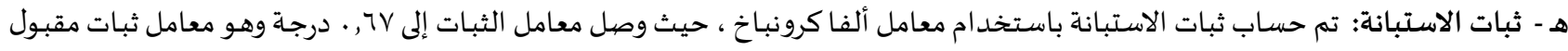
لمثل هذه الأداة.

ثالثاً : تحديد العينة : مذه الاداة

تم اختيار عينة البحث من طلاب عمادة البرامج التحضيرية بجامعة الإمام محمد بن سعود الإسلامية بطريقة عشوائية حيث بلغت العينة

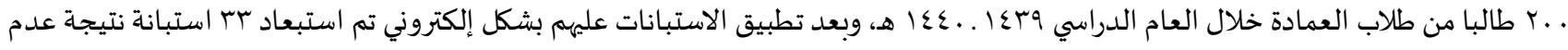

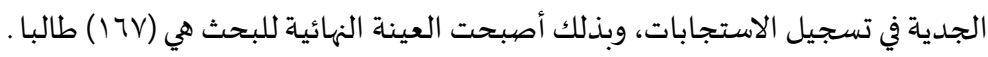
رابعاً : المعالجة الإحصائية :

$$
\begin{aligned}
& \text { استخدم الباحث في معالجاته الإحصائية الأساليب التالية: }
\end{aligned}
$$

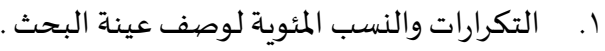

$$
\begin{aligned}
& \text { r r معامل ألفا كرونباخ لضبط الاستبانة. }
\end{aligned}
$$

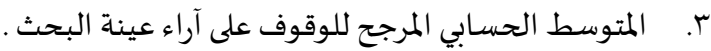

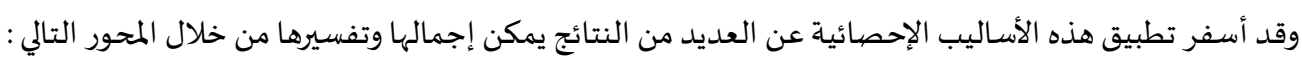
خامساً: نتائج البحث وتفسير تهدها: يستهدف هذا المحور عرض نتائج البحث المتعلقة بأسئلة البحث وفروضاه وتفسيرها ، وتحقيقا لهذا الهدف يتم تناول الآتي: أ- نتائج تتعلق بإجابة سؤال البحث الحالي:

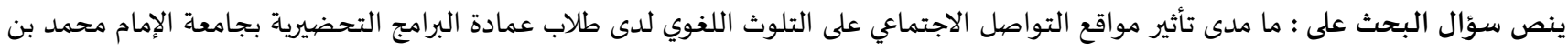
سعود الإسلامية من وجهة نظرهم؟ سوال

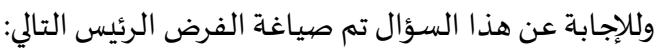

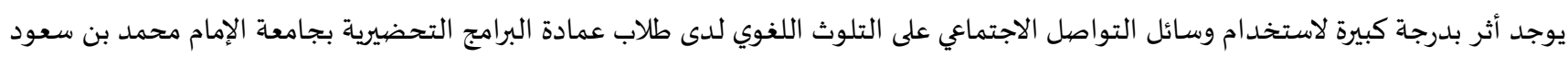

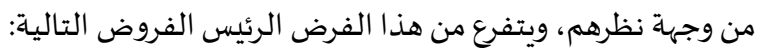
• يوجد أثر بدرجة كبيرة لاستخدام وسائل التواصل الاجتماعي على التلوث اللغوي (التلوث اللغوي بشكل عام) لدى طلاب عمادة البرامج التحضيرية

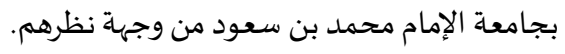
• يوجد أثر بدرجة كبيرة لاستخدام وسائل التواصل الاجتماعي على التلوث اللغوي (التلوث الهجيني) لدى طلاب عمادة البرامج التحضيرية بجامعة الإمام محمد بن سعود من وجهة نظرهم. • يوجد أثر بدرجة كبيرة لاستخدام وسائل التواصل الاجتماعي على التلوث اللغوي (التلوث الصوتي) لدى طلاب عمادة البرامج التحضيرية بجامعاة الإمام محمد بن سعود من وجهة نظرهم. • يوجد أثر بدرجة كبيرة لاستخدام وسائل التواصل الاجتماعي على التلوث اللغوي (التلوث الصرفي) لدى طلاب عمادة البرامج التحضيرية بجامعاة الإمام محمد بن سعود من وجهة نظرهم. • يوجد أثر بدرجة كبيرة لاستخدام وسائل التواصل الاجتماعي على التلوث اللغوي (التلوث النحوي) لدى طلاب عمادة البرامج التحضيرية بجامعاة الإمام محمد بن سعود من وجهة نظرهم. 
• يوجد أثر بدرجة كبيرة لاستخدام وسائل التواصل الاجتماعي على التلوث اللغوي (التلوث الدلالي) لدى طلاب عمادة البرامج التحضيرية بجامعة الإمام محمد بن سعود من وجهة نظرهم.

• يوجد أثر بدرجة كبيرة لاستخدام وسائل التواصل الاجتماعي على التلوث اللغوي (التلوث الإملائي) لدى طلاب عمادة البرامج التحضيرية بجامعة الإمام محمد بن سعود من وجهة نظرهم.

• يوجد أثر بدرجاة كبيرة لاستخدام وسائل التواصل الاجتماعي على التلوث اللغوي (التلوث العامي) لدى طلاب عمادة البرامج التحضيرية بجامعة الإمام محمد بن سعود من وجهة نظرهم.

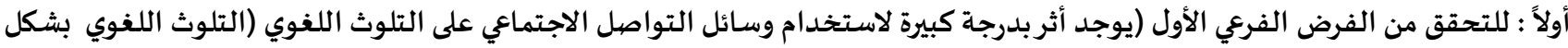

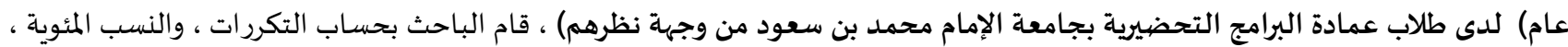

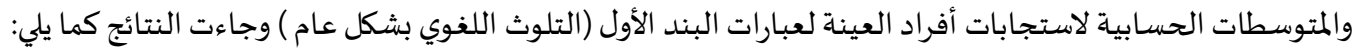

جدول (1): الذي يوضح متوسط استجابات عينة البحث على عبارات البند الأول (التلوث اللغوي بشكل عام)

\begin{tabular}{|c|c|c|c|}
\hline الانحراف المعياري & المتوسط & عدد الطلاب & \\
\hline . & r.q & $17 \mathrm{~V}$ & (بشكل عام) التلوث اللغوي \\
\hline
\end{tabular}

وتم حساب المتوسط حسب المقياس الخماسي للمتوسط المرجح. الذي سيطبقه الباحث في جميع نتائج البحث الحالي الآتي: جدول(Y) (Y) الذي يوضح طريقة حساب المتوسط المرجح

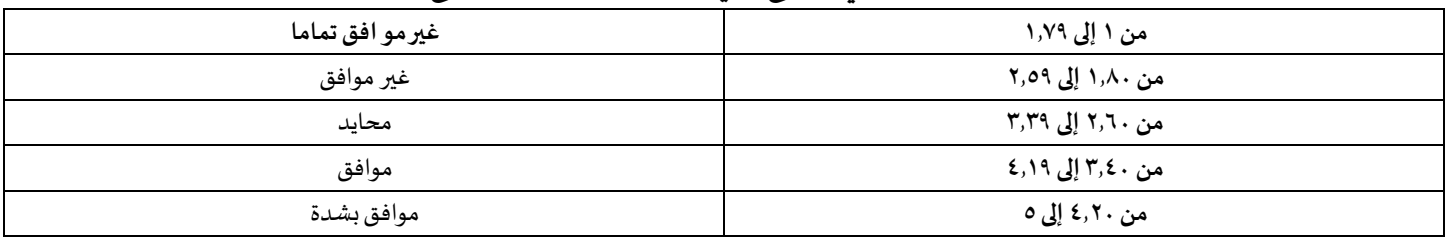

يتضح من الجدول (1) أن المتوسط الحسابي لدرجة موافقة عينة البحث على عبارات البند الأول (التلوث اللغوي بشكل عام) ع,ب ، وهو ما يعني أن موافقة عينة البحث على عبارات هذا البند ، مما يدل على وجود أثر كبير لمواقع التواصل الاجتماعي على التلوث اللغوي بشكل عام، وبذلك يستطيع الباحث أن يحكم على وجود أثر لمواقع التواصل الاجتماعي على التلوث اللغوي بشكل عام ويرجع ذلك - من وجهة نظر الباحث - إلى أن تواجد الطلاب

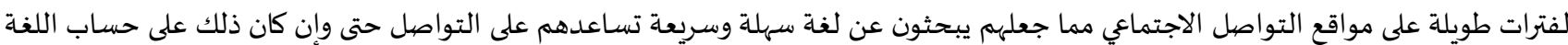

الفصيحة وقواعدها. ثانياً: للتحقق من الفرض الفرعي الثاني (يوجد أثر بدرجة كبيرة لاستخدام وسائل التواصل الاجتماعي على التلوث اللغوي (التلوث الهجيني) لدى لداء طلاب عمادة البرامج التحضيرية بجامعة الإمام محمد بن سعود من وجهة نظرهم)، قام الباحث بحساب التكرارات، والنسب المئوية، والمتوسطات الحسابية لاستجابات أفراد العينة لعبارات البند الثاني (التلوث الهجيني) وجاءت إجمالي النتائج كما يلي:

جدول (r): الذي يوضح متوسط استجابات عينة البحث على عبارات البند الثاني (التلوث الهجيني)

\begin{tabular}{|c|c|c|c|}
\hline الانحراف المعياري & المتوسط & عدد الطلاب & \\
\hline .,VATVI & $r, 7170$ & $17 V$ & التلوث الهجيني \\
\hline
\end{tabular}

يتضح من الجدول (r) أن المتوسط الحسابي لدرجة موافقة عينة البحث على عبارات البند الثاني (التلوث الهجيني) ج,r ، وهو ما يعني موافقة عينة البحث على عبارات هذا البند ، مما يدل على وجود أثر كبير لمواقع التواصل الاجتماعي على التلوث الهجيني، وبذلك يستطيع الباحث أن يحكم على

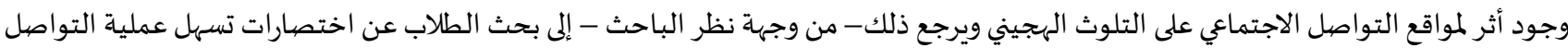
مما يجعلهم يستخدمون بعض الحروف اللاتينية أو بعض حروف اللغة الإنجليزية وكذلك استخدام الأرقام والرموز.

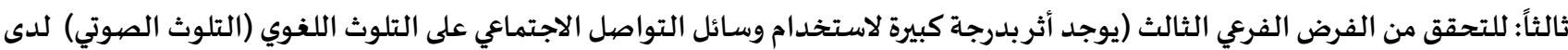
طلاب عمادة البرامج التحضيرية بجامعة الإمام محمد بن سعود من وجهة نظرهم)، قام الباحث بحساب التكرارات، والنسب المئوية، والمتوسطات

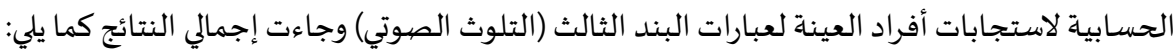


جدول( ع): الذي يوضح متوسط استجابات عينة البحث على عبارات البند الثالث (التلوث الصوتي)

\begin{tabular}{|c|c|c|c|}
\hline التيn| & \multirow{2}{*}{ التلوث } \\
\hline
\end{tabular}

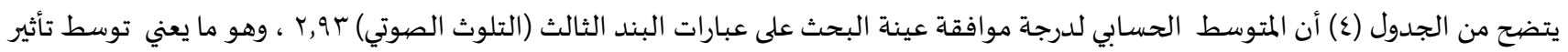

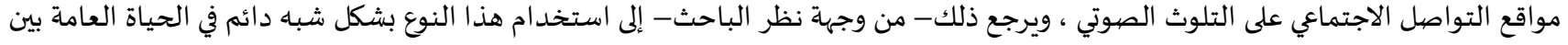

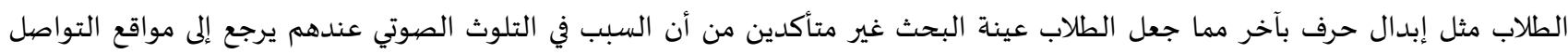

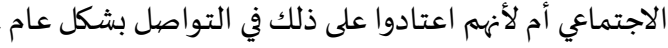

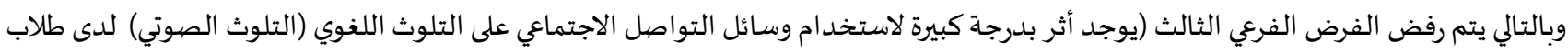

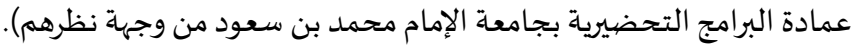

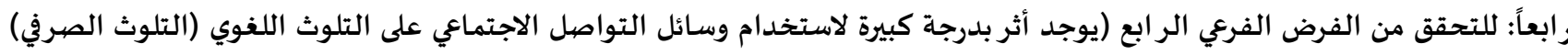

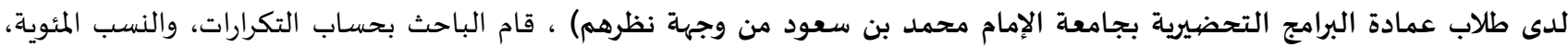

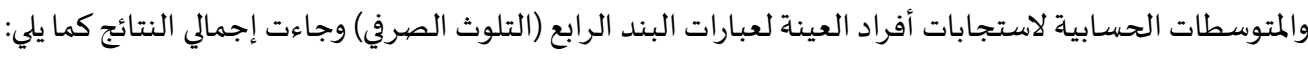

جدول (0): الذي يوضح متوسط استجابات عينة البحث على عبارات البند الر ابع (التلوث الصرفي)

\begin{tabular}{|c|c|c|c|}
\hline الانحراف المعياري & المتوسط & عدد الطلاب & \\
\hline .,$Y \sum 9 \vee 7$ & $r, \Lambda \Sigma T V$ & 178 & التلوث الصرفي \\
\hline
\end{tabular}

يتضح من الجدول (o) أن المتوسط الحسابي لدرجة موافقة عينة البحث على عبارات البند الرابع (التلوث الصرفي) ، عد, r وهو ما يعني توسط تأثير

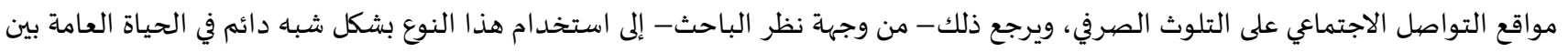

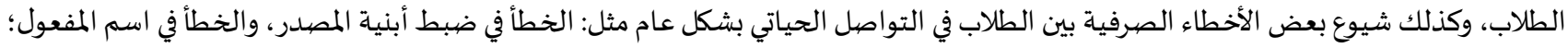

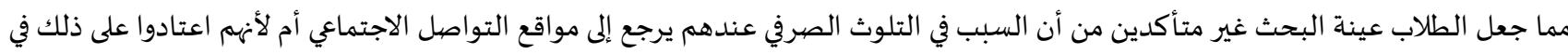
التواصل بشكل عام . وبالتالي يتم رفض الفرض الفرعي الرابع (يوجد أثر بدرجة كبيرة لاستخدام وسائل التواصل الاجتماعي على التلوث اللغوي (التلوث الصرفي) لدى طلاب

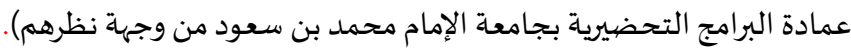

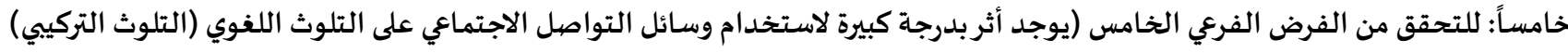

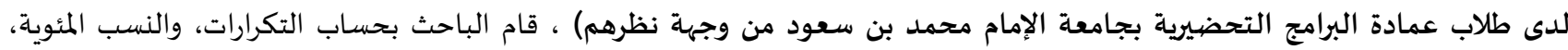
والمتوسطات الحسابية لاستجابات أفراد العينة لعبارات البند الخامس (التلوث التركيبي) وجاءت إجمالي التماني النتائج كما يلي:

جدول( (7): الذي يوضح متوسط استجابات عينة البحث على عبارات البند الخامس (التلوث التركيبي)

\begin{tabular}{|c|c|c|c|}
\hline الانحراف المعياري & المتوسط & عدد الطلاب & \\
\hline$., V r, T r$ & $\left.r, \Lambda \sum q\right)$ & 178 & التلوث التركيبي \\
\hline
\end{tabular}

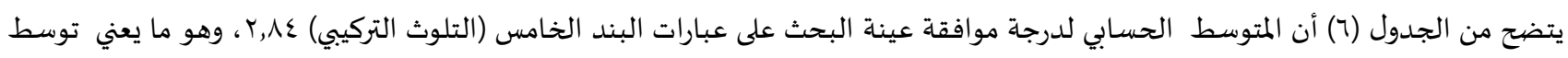

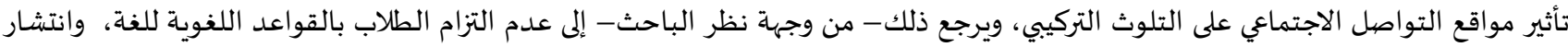

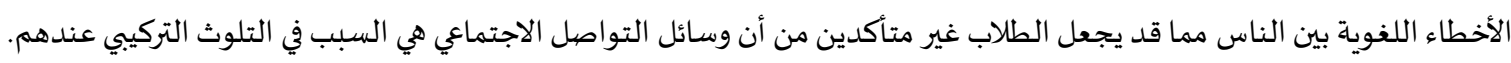

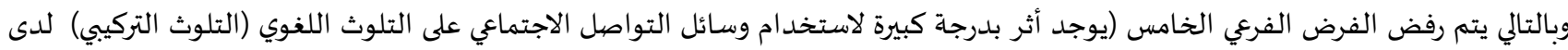

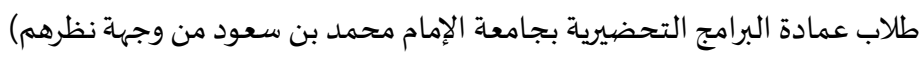

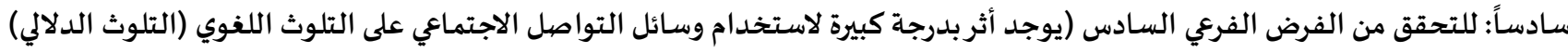

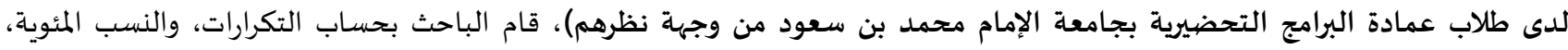

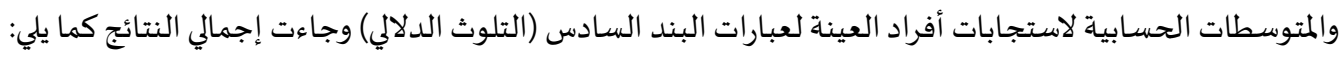


جدول(V): الذي يوضح متوسط استجابات عينة البحث على عبارات البند السادس (التلوث الدلالي)

\begin{tabular}{|c|c|c|c|}
\hline التيn| & \multirow{2}{*}{ التلوي } \\
\hline
\end{tabular}

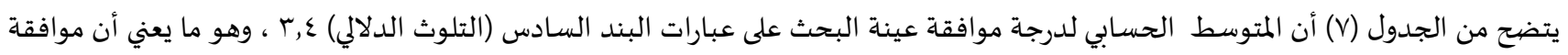

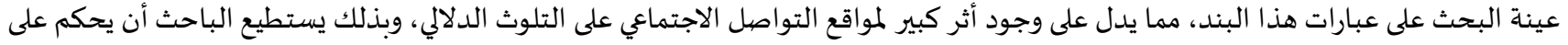

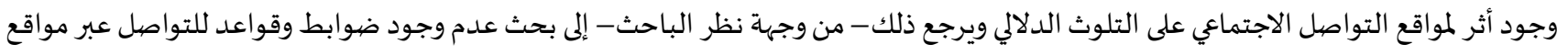

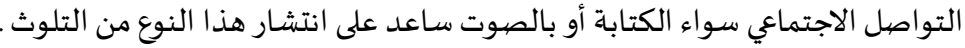

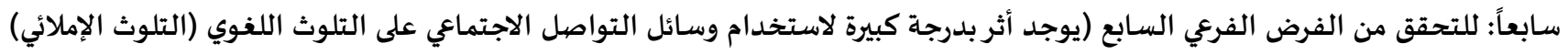

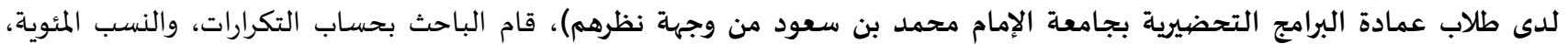

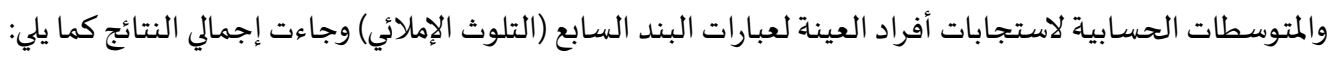

جدول(^): الذي يوضيح متوسط استجابات عينة البحث على عبارات البند السابع (التلوث الإملائي)

\begin{tabular}{|c|c|c|c|}
\hline الانحراف المعياري & المتوسط & عدد الطلاب & \\
\hline $1, . \vee \wedge 01$ & $r, 0 . \wedge \varepsilon$ & $17 \mathrm{~V}$ & التلوث الإملائي \\
\hline
\end{tabular}

يتضح من الجدول (^) أن المتوسط الحسابي لدرجة موافقة عينة البحث على عبارات البند السابع (التلوث الإملائي) ه, r، وهو ما يعني عدم موافقة

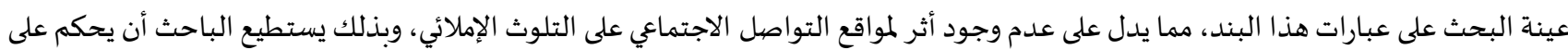

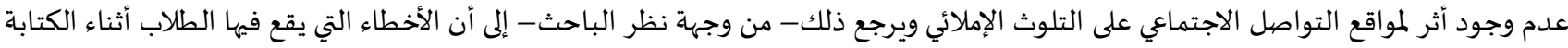

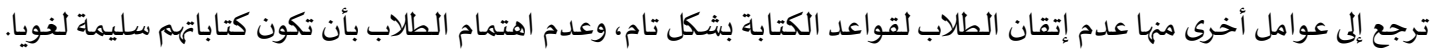
وبالتالي يتم رفض الفرض الفرعي السابع (يوجد أثر بدرجة كبيرة لاستخدام وسائل التواصل الاجتماعي على التلوث التران اللغوي (التلوث الإملائي) لدى طلاب

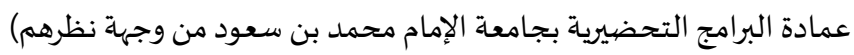

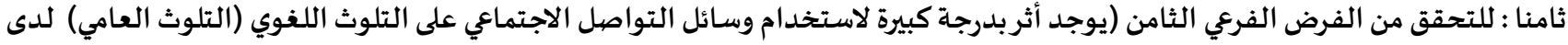

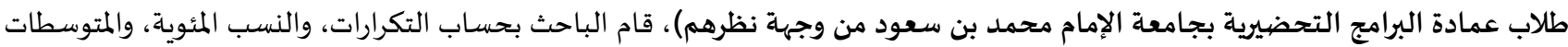
الحسابية لاستجابات أفراد العينة لعبارات البند الثامن (التلوث العامي) وجاءت إجمالئ التهائ النتائج كما يلي:

جدول(9): الذي يوضح متوسط استجابات عينة البحث على عبارات البند الثامن (التلوث العامي)

\begin{tabular}{|c|c|c|c|}
\hline الانحراف المعياري & المتوسط & عدد الطلاب & \\
\hline . & $\varepsilon$, r А Y & $17 \mathrm{~V}$ & التلوث العامي \\
\hline
\end{tabular}

يتضح من الجدول (9) أن المتوسط الحسابي لدرجة موافقة عينة البحث على عبارات البند الثامن (التلوث العامي) ع, ، ، وهو ما يعني موافقة عينة

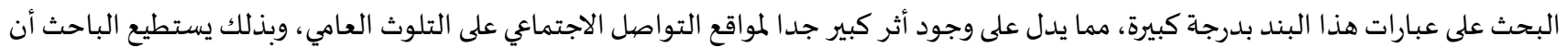

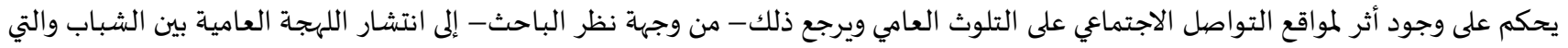

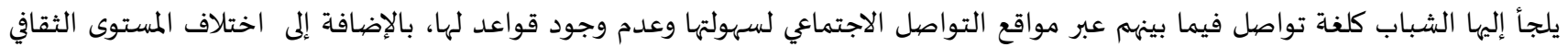

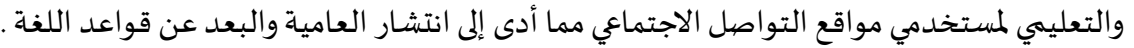

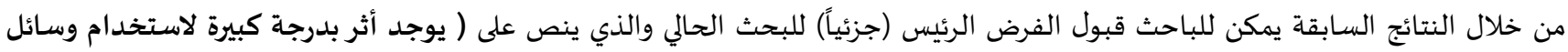

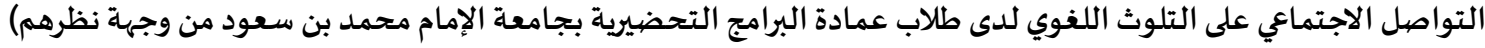

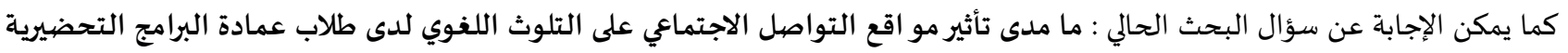

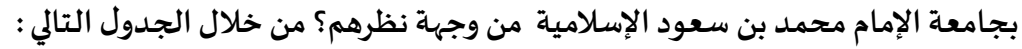
جدول ( ـ (): الذي يوضح متوسط استجابات عينة البحث على فقرات بنود الاستبانة

\begin{tabular}{|c|c|c|c|}
\hline المتوسط & 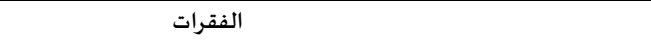 & البند الرئيس البيس & م \\
\hline$r, v 0 \leqslant \leqslant 91.11$ & تضعف مواقع التواصل الاجتماعي من العناية باللغة العربية & \multirow[b]{5}{*}{ 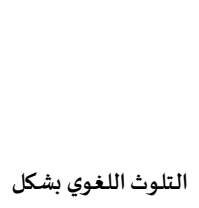 } & 1 \\
\hline r,Arrtrotrq & تؤدي مواقح التواصل الاجتماعي إلى حدوث التغريب اللغوي & & r \\
\hline r,OTAMTrTVO & تؤثر مواقع التواصل الاجتمائي في مستوى اللغة العربية الفصيحة لديًّ بالسلب & & $r$ \\
\hline$r, A V \varepsilon Y O \mid \sum 9 V$ & تؤدي مواقع التواصل الاجتماعي إلى طمس هوية الحرف العربي & & $\varepsilon$ \\
\hline$r, \varepsilon r 01 \leqslant q v \cdot 1$ & تضعف مواقع التواصل الاجتمايي الحصيلة اللغوية لديّ & & $\circ$ \\
\hline
\end{tabular}




\begin{tabular}{|c|c|c|c|}
\hline r,VYE00.人91 & تؤدي مواقع التواصل الاجتماعي إلى إحداث تراكم لغوي لا علاقة له باللغة العربية & \multirow[t]{3}{*}{ عام } & 7 \\
\hline r,rYI TOVENo & أستخدم اللغة العربية الفصيحة في تواصلي المكتوب مع الآخرين عبر مواقع التواصل الاجتماعي & & $\mathrm{v}$ \\
\hline$r, \Sigma 9 \vee \ldots .0911$ & أجد صعوبة في استخدام اللغة العربية الفصيحة في التواصل مع أصدقائي عبر مواقع التواصل الاجتماعي & & $\wedge$ \\
\hline 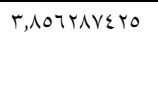 & بالباء "لبيه" حرفًا مكان حرف في أثناء تواصلي عبر مواقع التواصل الاجتماعي مثل: إبدال حرف الكاف في كلمة "لبيك" & \multirow[t]{3}{*}{ 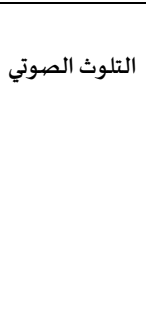 } & 9 \\
\hline 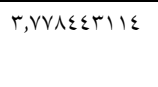 & "أبُبة كرة القدمة بأخرى في أثناء تواصلي عبر مواقع التواصل الاجتماعي (مثل: أن اقول "لِعبة كرة القدم" بدلا من & & 1. \\
\hline r,r1007MN7r & بدلا من "رتاجة من حروف اللين على الكلمة في أثناء تواصلي عبر مواقع التواصل الاجتماعي (مثل: أن أقول "ريتاج" & & 11 \\
\hline r,E乏rIIrVVr & 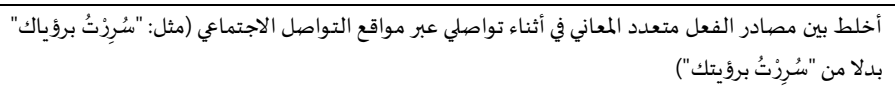 & \multirow{3}{*}{ 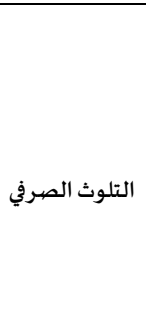 } & it \\
\hline r,\&Vr. Or人qr & "أخطئ في ضبط أبنية المصلدر في أثناء تواصليًا عبر مواقح التواصل الاجتماعي (مثل: "ذهب فلان ذِهابًا" بدلا من & & 14 \\
\hline r,人9rr10079 & "مبارك") أخطئ في اسم المفعول في أثناء تواصلي عبر مواقع التواصل الاجتماعي (مثل: أن أقول "مبروك" بدلا من & & $1 \varepsilon$ \\
\hline 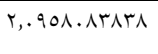 & ألتزم قواعد النحو العربي عند الكتابة على مواقع التواصل الاجتماعي & \multirow{3}{*}{ التلوث التركيبي } & 10 \\
\hline 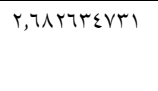 & أُدخل حرف التعريف "ألل" على "لا" النافية في أثناء تواصلي عبر مواقع التواصل الاجتماعي (مثل: "هذا من & & 17 \\
\hline$r, V V r \varepsilon 00.9$ & من "أُسقط حرف الجر في بعض الجمل في أثناء تواصلي عبر مواقع التواصل الاجتماعي (مثل: "فلان يحتاجُني" بدلا & & iv \\
\hline$r, .091 \Lambda \cdot r \varepsilon$ & "بكى من شـدة التأثر" مبن معادر في أثناء تواصلي عبر مواقع التواصل الاجتماعي مثل: "بكى من شدة التأثير" بدلا من & \multirow[t]{3}{*}{ 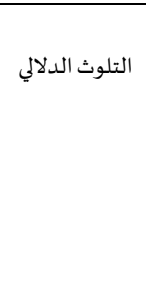 } & 11 \\
\hline r.r90r.9011 & أقلب المعنى في أثناء تواصلي عبر مواقع التواصل الاجتماعي (مثل: أن أقول "عجبتُ منه" بدلا من أعجبني") & & 19 \\
\hline$r, 1 \cdot V \vee \wedge \varepsilon \varepsilon r 1$ & تواصلط بين معاني ظروف الزمان (مثل: أن أقول "غادر فلان قبل بُرهة" بدلا من " غادر قبل هُنهية") في أثناء & & r. \\
\hline r,IrVVr£001 & أخلط بين التاءين: المربوطة، والمفتوحة في أثناء تواصلي عبر مواقع التواصل الاجتماعي & \multirow{3}{*}{ التلوث الإملائي } & $r$ \\
\hline 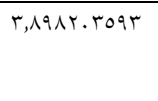 & أُ أثناء تباستخدام علامات الترقيم (مثل : علامة الاستفهام "؟" ، والفاصلة "،" ، وعلامة التعجب "!" وغيرها) في & & rt \\
\hline r,rorrarsir & أخلط بين همزة القطع وألف الوصل (مثل: أن أكتب أسكت بدلا من اسكت) عند تواصلي عبر مواقع التواصل & & r \\
\hline$r, v \ldots .0911 . r$ & أستخدم الاختصارات التي تظهر باللغة اللاتينية مثل: LOLوتعني (يضحك بصوت عال) عبر مواقع التواصل & \multirow{3}{*}{ 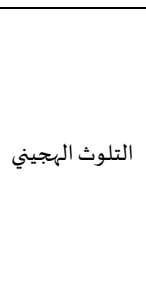 } & $r \varepsilon$ \\
\hline$r, \varepsilon \varepsilon q 1 . \mid V 97$ & أستخدم الاختصارات التي تظهر باللغة اللاتينية مثل: LOLوتعني (يضحك بصوت عال) عبر مواقع التواصل & & ro \\
\hline T,r人rrmorr & أستخدم الأرقام والرموز بدلا من الحروف في كتابتي عبر مواقع التواصل الاجتماعي & & ru \\
\hline$\varepsilon$, YA9TY100V & 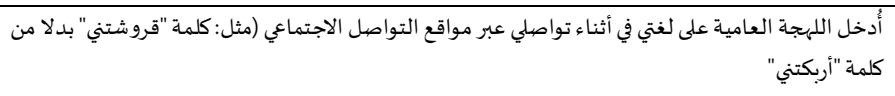 & 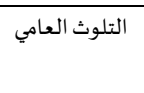 & TV \\
\hline
\end{tabular}


يوضح الجدول السـابق متوسط استجابة عينة البحث لكل فقرة من فقرات بنود الاستبانة، والجدول التالي يوضح متوسط استجابات عينة البحث على جميع بنود الاستبانة

جدول(1) (1): الذي يوضح متوسط استجابات عينة البحث على جميع بنود الاستبانة

\begin{tabular}{|c|c|c|c|}
\hline الانحراف المعياري & المتوسط & عدد الطلاب & المحور \\
\hline., 7.187 & $r, \varepsilon \ldots$ & 178 & التلوث بشكل عام \\
\hline ., vArvr & r,qror & $17 V$ & التلوث الصهوتي \\
\hline ., V々9V7 & $r, \wedge \leqslant 7 V$ & $17 V$ & التلوث الصرفي \\
\hline., $\mathrm{VT} \cdot \mathrm{rr}$ & $r, \wedge \sum q 1$ & 178 & التلوث التركيبي \\
\hline$\cdot, \lambda .\{\wedge 1$ & $r, \varepsilon>\varepsilon V$ & 178 & التلوث الدلالي \\
\hline $1, . \vee \wedge 101$ & $r, 0 . \wedge \varepsilon$ & $17 V$ & التلوث الإملائي \\
\hline ., VATVI & $r, 7107$ & $17 V$ & التلوث الهجيني \\
\hline., $97 r K \varepsilon$ & $\varepsilon$, rА१५ & $17 V$ & التلوث العامي \\
\hline .,NIKYIQ & r, rollro & & المتوسط العام \\
\hline
\end{tabular}

من خلال جدول (11) يكون المتوسط العام لجميع المحاور هو Y, r وهذا يعني وجود تأثير متوسط ويقارب إلى درجة كبير لمواقع التواصل الاجتماعي على التلوث اللغوي بشكل جزئي ومن خلال الجدول رقم (. 1) والجدول رقم (1 ا) يمكن استنتاج أن هناك تأثير لمواقع التواصل الاجتماعي على التلوث اللغوي ـ بشكل جزئي ـ لدى طلاب عمادة البرامج التحضيرية بجامعة الإمام محمد بن سعود الإسلامية من وجهة نظرهم، في جميع المحاور عدا المحتور الخامس (التلوث الإملائي)

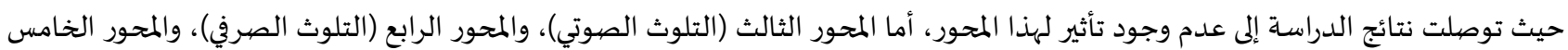

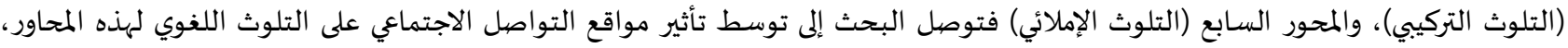

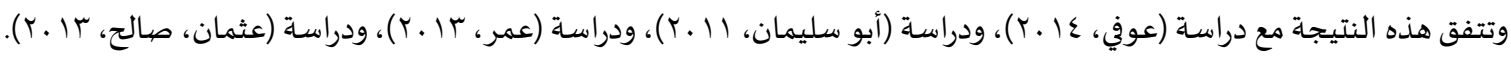

$$
\text { التوصيات والمقترحات: }
$$

في ضوء نتائج البحث يمكن التوصل إلى مجموعة من التوصيات والمقترحات

التوصيات: في ضوء ما توصل إليه البحث الحالي يوصي الباحث بما يلي: • عقد دورات وورش عمل لطلاب البرامج التحضيرية لرفع الكفاءة اللغوية لديهم. عقد ندوات لطلاب البرامج التحضيرية لتوعيتهم بأهمية اللغة العربية واستخد امها تحدثا وكتابة.

عقد مسابقات في اللغة العربية لتشجيع الطلاب على الاهتمام بها.

المقترحات: يمكن التوصل لعدد من الأفكار البحثية المنبثقة من البحث الحماب البعالي كما يلي: مدى تأثير مواقع التواصل الاجتماعي على التلوث اللغوي لدى طلاب المرحلة الثانوية. العلاقة بين التلوث اللغوي ونوعية المدارس (الأهلية . الخاصية) التي يدرس بها طلاب المملكة العربية السعودية. • تأثير مواقع التواصل الاجتماعي على مهارات التواصل الشفهي والكتابي لدى طلاب الجامعة.

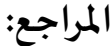

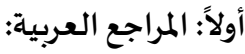

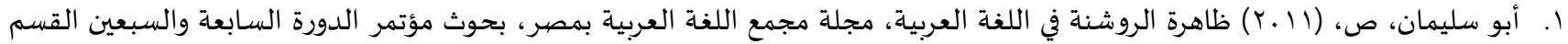

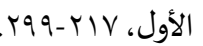

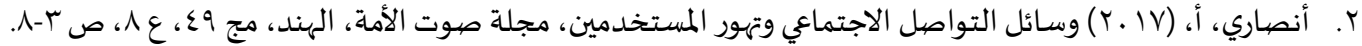

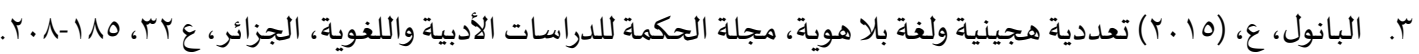

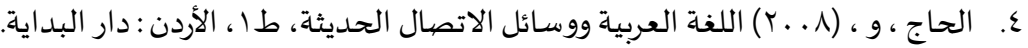

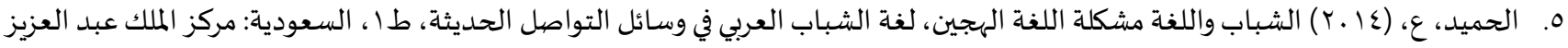
الدولي لخدمة اللغة العربية.

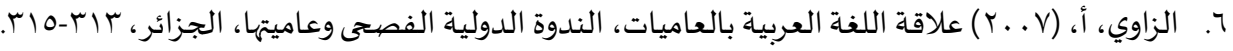




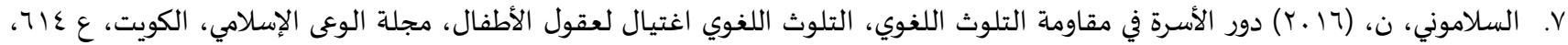
$. \vee \wedge: \vee 9$

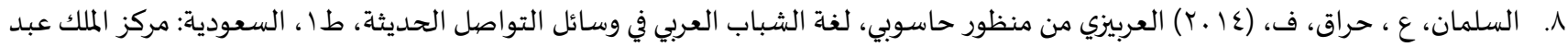
الله بن عبد العزيز الدولي.

9.

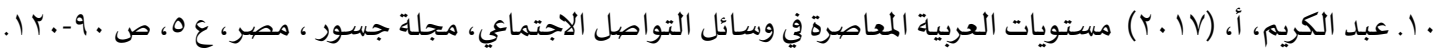

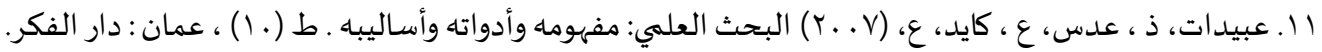

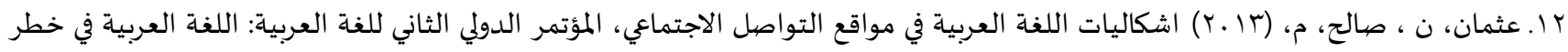
الجميع شركاء في حمايتها.

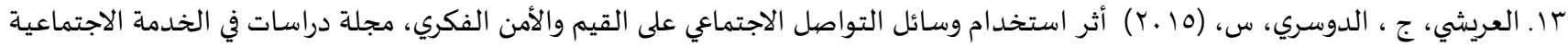

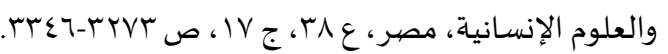

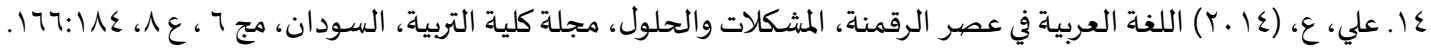

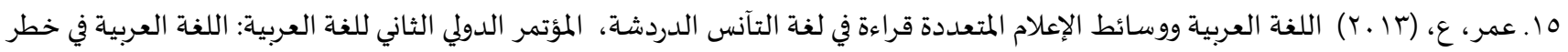

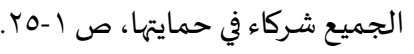

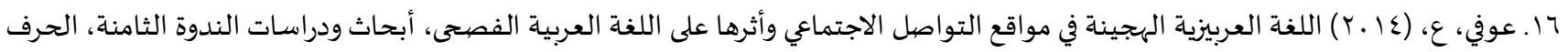

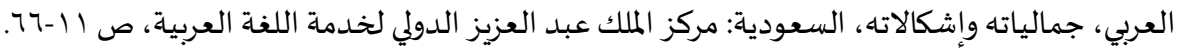

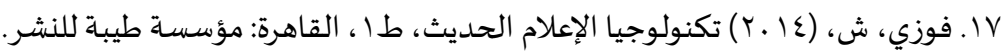

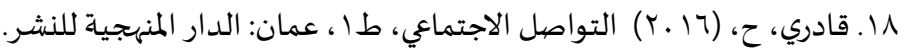

9 ا. القرني، م ، وآخرون، (10 ـ ب) . واقع النشاط اللغوي في مواقع التواصل الاجتماعي تويتر نموذجًا، طا ، السعودية: مركز الملك عبد العزيز الدولي لخدمة اللغة العربية.

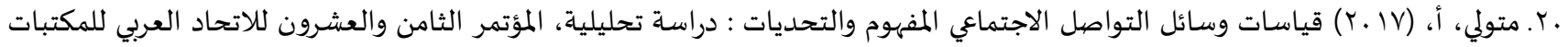

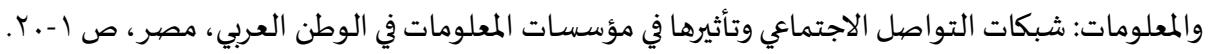

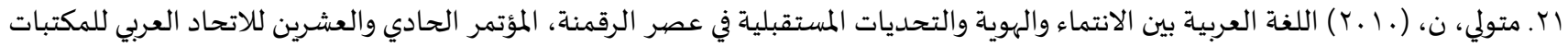

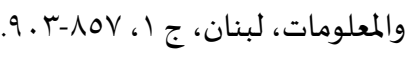

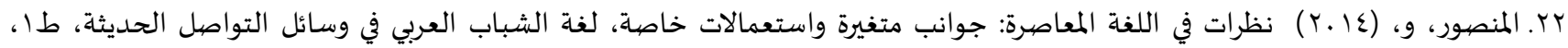
السعودية: مركز الملك عبد العزيز الدولي لخدمة اللغة العبد العربية.

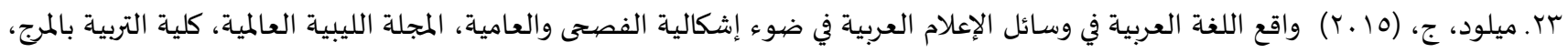
جامعة بنغازي، ع9، 19-19.

ثانياً: المراجع الأجنبية:

[1] Reitz. Ammy, Social Media's Function in Organizations: A Functional Analysis Approach, Global Media Journal -- Canadian Edition, 5(2)(2012), 41-56.

[2] Salem. F., The Arab Social Media Report 2017: Social Media and the Internet of Things: Towards DataDriven Policymaking in the Arab World 7(2017), Dubai: MBR School of Government. 
Refaad

رفاد للدراسات والأبحاث

www.refaad.com
المجلة الدولية للدراسات التربوبة والنفسية

e-ISSN 2520-4149 , p-ISSN 2520-4130

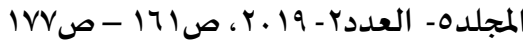

https://doi.org/DOI:10.31559/EPS2019.5.2.5
المجلة الدولية للدراسات

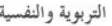

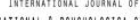
EDUCATIONAL \& PSYCHOLOGICA STUDIS

\title{
The Effect of Social Media on Language Pollution among Students of the Deanship of Preparatory Programs at Imam Muhammad Bin Saud Islamic University From their Point of View
}

\author{
Mohamed Ahmed Ahmed Fathi Zoghary \\ Assistant Professor of Curriculum and Teaching Methods of Arabic Language to the Deanship of Preparatory \\ Programs- Imam Muhammad Bin Saud Islamic University \\ dr_design2010@yahoo.com
}

\begin{abstract}
:
The objective of this study is to determine the effect of social media on language pollution among students of the Deanship of Preparatory Programs at Imam Muhammad Bin Saud University. In order to achieve this goal, the researcher identified the concept of linguistic pollution, its classifications and reasons, And the researcher built a questionnaire included (8) items are: linguistic pollution in general, and the pollution of the hybrid, and pollution, and verbal pollution, and synthetic pollution, and the pollution of semantic, and spelling pollution, and public pollution, And then the researcher applied the questionnaire to (200) students of the Deanship of preparatory programs at the University of Imam Muhammad bin Saud Islamic, and found that the study that the impact of social media in part on the linguistic contamination in the sample study.
\end{abstract}

Keywords: language pollution, social media, deanship preparatory programs students.

\section{References:}

[1] 'bd Ạlkrym. Ạ̉, Mstwyạt Ạl'rbyh Ạlm 'ạṣrh Fy Wsậl Ạltwạṣl Ạlạjtmạ y, Mjlï Jswr , Mṣr, (5)(2017), 90120.

[2] 'bydạt. Dḥ , 'ds. ' \& Kạyd. ', Ạlbḥthِ Ạl'lmy: Mfhwmh Wạ̉dwạth Wạ̉sạlybh, Ṭ(10), 'mạn: Dạr Ạlfkr, (2007).

[3] 'ly. ', Ạllghhh Ạl'rbyh Fy 'ṣr Ạlrqmnh, Ạlmsḥklạt Wạlḥ̣lwl, Mjlï Klyẗ Ạltrbyh, Ạlswdạn, 6(8)(2014), 166184.

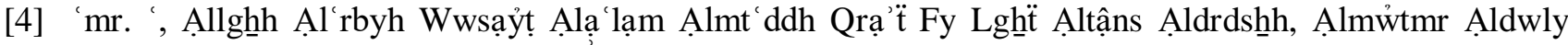

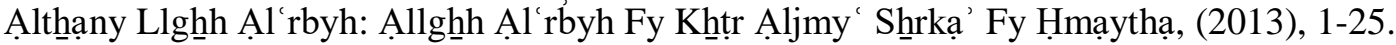

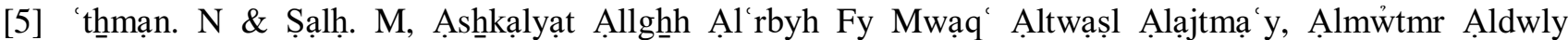

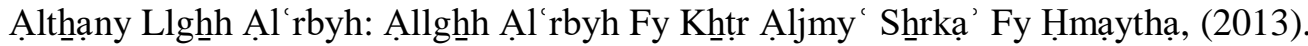

[6] 'wfy. ', Allgḥh Ạl rrbyzyh Ạlhjynh Fy Mwạq' Ạltwạṣl Ạlạjtmạ y Wạ̉thrhạ 'la Ạllghhh Ạl'rbyh Ạlfṣha,

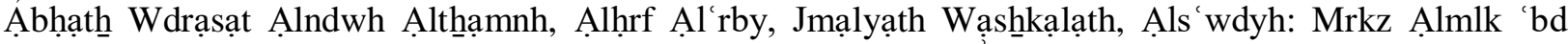
Ạl'zyz Ạldwly Lkhdmë Ạllghh Ậl'rbyh, (2014), 11-66.

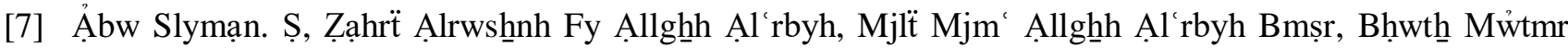
Ạldwrh Ạlsạb ‘h Wạlsb yn Ạlqsm Ạlạ̉wl, (2011), 217-299. 


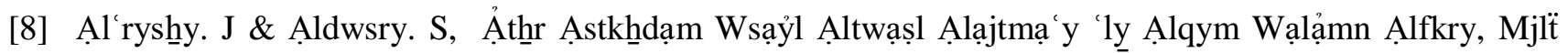
Drạsạt Fy Ạlkhِdmh Ạlạjtmạ yh Wạl 'lwm Ạlạnsạnyh, Mṣr, 17(38)(2015), $\overline{3} 273-3346$.

[9] Ạlbạnwl. ', T'ddyh Hjynyh Wlghhh Blạ Hwyh, Mjlt Ạlḥkmh Lldrạsạt Ạlạ̉dbyh Wạllghnwyh, Ạljzậrr, (32)(2015), 185-208.

[10] Ạlhạjj. W, Ạllghhh Ạl rbyh Wwsạyl Ạlạtṣạl Ạlḥdytḥh, Ṭ1, Ạlạ̉rdn : Dạr Ạlbdạyh, (2008).

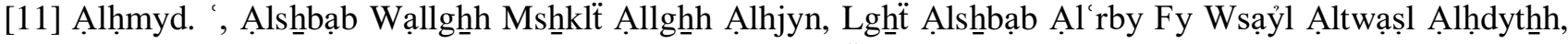
Ṭ1, Ạls 'wdyh: Mrkz Ạlmlk 'bd Ạl'zyz Ạldwly Lkhַdmë Ạllgḥh Ạl'rbyh, (2014).

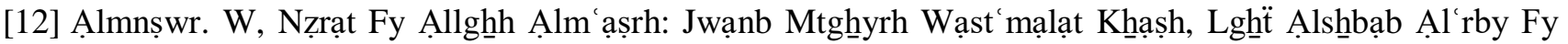

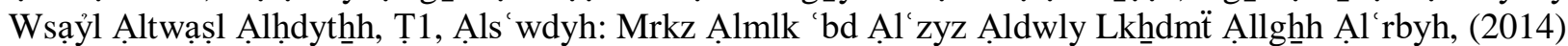

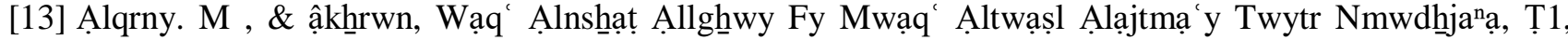
Ạls 'wdyh: Mrkz Ạlmlk 'bd Ạl'zyz Ạldwly Lkhdmë Ạllghh Ạl'rbyh, (2015).

[14] Ạlslmạn. ' \& Ḥrạq. F, All'rbyzy Mn Mnẓwr Hạswby, Lgḥ̈t Ạlsḥbạb Ạl'rby Fy Wsạỷl Ạltwạạl Ạlḥdytḥh, Ṭ1, Ạls'wdyh: Mrkz Ạlmlk 'bd Ạllh Bn ‘bd Ạl'zyz Ạldwly, (2014).

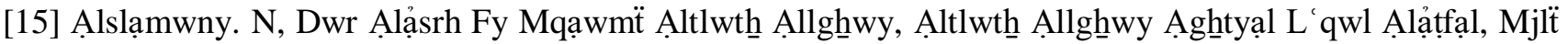
Ạlw'y AlạSlạmy, Ạlkwyt, (614)(2016), 78:79.

[16] Ạlsyd. M, Msḥklạt Ạllgḥh Ạl'rbyh, Mjlï Mjm` Ạllgḥh Ạl'rbyh, 127(2014), 176- 207.

[17] Ạlzạwy. Ạ̉, 'lạqë Ạllghh Ạl'rbyh Bạl'ạmyạt, Ạlndwh Ạldwlyh Ạlfṣḥ̣y W'ạmythạ, Ạljzậ̉r, (2007), 313315.

[18] Ạ̉nșạry. Ạ, Wsạyl Ạltwạ̣̣l Ạlạjtmạ y Wthwr Ạlmstkhַdmyn, Mjlt Șwt Ạlạ̉mh, Ạlhnd, 49(8)(2017), 3-8.

[19] Fwzy. Sh̆, Tknwlwjyạ Ạlạ lạm Ạlḥ̣dytḥ, Ṭ1, Ạlqạhrh: Mw̉ssẗ̈ Ṭbh Llnsḥr, (2014).

[20] Mtwly. Ạ, Qyạsạt Wsạỷl Ạltwạṣl Ạlạjtmạ y Ạlmfhwm Wạltḥdyạt: Drạsh Tḥlylyh, Ạlmw̉tmr Ạlthạmn

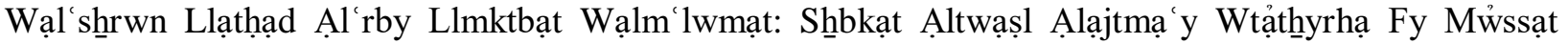
Ạlm lwmạt Fy Ạlwțn Ạl'rby, Mṣr, (2017), 1-20.

[21] Mtwly. N, Ạllghhh Ạl'rbyh Byn Ạlạntmạ’ Wạlhwyh Wạltḥdyạt Ạlmstqblyh Fy 'ṣr Ạlrqmnh, Ạlmw̉tmr Ạlhạdy Wạl'shryn Llạthạd Ạl'rby Llmktbạt Wạlm' lwmạt, Lbnạn, 1(2010), 857-903.

[22] Mylwd. J, Wạq Ạllghh Ạl 'rbyh Fy Wsạỷl Ạlạ lạm Ạl'rbyh Fy Ḍw’ ẠShkạlyh Ạlfṣhy Wạl 'ạmyh, Ạlmjlh Ạllybyh Ạl'ạlmyh, Klyë Ạltrbyh Bạlmrj, Jạm't́t Bnghạzy, (9)(2015),1-19.

[23] Qạdry. Ḥ, Ạltwạṣl Ạlạjtmạ y, Ṭ1, 'mạn: Ạldạr Ạlmnhjyh Llnsḥr, (2016).

[24] Reitz. Ammy, Social Media's Function in Organizations: A Functional Analysis Approach, Global Media Journal -- Canadian Edition, 5(2)(2012), 41-56.

[25] Salem. F., The Arab Social Media Report 2017: Social Media and the Internet of Things: Towards DataDriven Policymaking in the Arab World 7(2017), Dubai: MBR School of Government. 